\title{
Loading applied on osseointegrated implant by transtibial bone-anchored prostheses during daily activities: Preliminary characterization of prosthetic feet
}

\author{
Laurent Frossard $^{(1)}$, Barry Leech ${ }^{(2)}$, Mark Pitkin ${ }^{(3)}$ \\ (1) Queensland University of Technology, Brisbane, QLD, Australia \\ (2) Barry Leech Prosthetics \& Orthotics Pty Ltd, Southport, QLD, Australia \\ (3) Department of Physical Medicine and Rehabilitation, Tufts University, Boston, MA, USA
}

\begin{abstract}
Manuscript as published in "Frossard L, Leech B, Pitkin M. Loading applied on osseointegrated implant by transtibial bone-anchored prostheses during daily activities: Preliminary characterization of prosthetic feet. Journal of Prosthetics and Orthotics. 2020. Online Frist."

https://journals.lww.com/jpojournal/Abstract/publishahead/Loading_Applied_on_Osseointegrated_Implant_by.998 $\underline{57 . a s p x}$
\end{abstract}

\begin{abstract}
Introduction. This case-series study laid out principles for characterization of loading profile applied on osseointegrated implant by transtibial bone-anchored prostheses fitted with various feet while presenting benchmark loading data.

Materials and Methods. Three individuals walked, ascended and descended stairs and ramps with instrumented prostheses fitted with a load cell as well as usual and anthropomorphic feet successively. The characterization of the loading profile involved the comparison of 100 variables including spatio-temporal characteristics, loading boundaries, local extremum and impulse.

Results. The absolute maximum load extracted from 319 gait cycles with both prostheses across all activities was 48 $\% \mathrm{BW}, 17 \% \mathrm{BW}$ and $112 \% \mathrm{BW}$ for the forces as well as $2 \% \mathrm{BWm}, 13 \% \mathrm{BWm}$ and $1 \% \mathrm{BWm}$ for the moments on and around the anteroposterior, mediolateral and long axes of the implant, respectively.

Discussion. New evidence presented here indicated that a specific and comprehensive loading characterization capable to differentiate transtibial bone-anchored prostheses was achievable when relying on tri-axial direct measurements, recording a range of daily activities in addition of walking and considering at least nine loading extremum.

Conclusions: Prosthetic care providers could use this characterization for evidence-based fitting of components to growing population of individuals with transtibial amputation fitted with osseointegrated implant worldwide.
\end{abstract}

Keywords

Amputation; Artificial limb; Bone-anchored prosthesis; Osseointegrated implants; Osseointegrated fixation; Osseointegration; Prosthesis; Loading; Kinetics; Feet

\section{INTRODUCTION}

Transtibial bone-anchored prostheses: Potential fitting option

Recent studies confirmed that osseointegrated implants enabling attachment of bone-anchored prosthesis (BAP) have the potential to provide significant clinical benefits to individuals with transfemoral amputation, particularly those who could not be fitted acceptably with socket-suspended prostheses (e.g., none-prosthetic users). ${ }^{[1-5]}$ Risks of loosening and recurrent superficial and deep infections as well as breakage of implant parts are deemed acceptable by treating teams, although there are yet to be satisfactorily resolved. ${ }^{[3,5-10]}$ Provision of transfemoral BAP appeared cost-effective compared to socketsuspended prostheses from a governmental perspective..$^{[11-13]}$
These promising outcomes have encouraged developments of innovative surgical procedures to treat more frequent, but possibly more complex, case-mixes including transtibial with amputation (TTA). ${ }^{[14,15]}$ For instance, a surgical procedure combining total knee replacement and insertion of press-fit osseointegrated implant was created to enable attachment of BAP for TTAs with short residuum. ${ }^{[15]}$

Little is known about the clinical outcomes of surgical direct skeletal attachment specific to TTA, particularly the benefits (e.g., function, health-related quality life, cost-effectiveness) and safety (e.g., loosening, infection, breakage of components). ${ }^{[6,15-17]}$ Nonetheless, in all cases, the control of infection during the lifetime of these patients is paramount to prevent the undesirable setback of a transfemoral amputation that will significantly further decrease their quality of life. ${ }^{[18]}$ 
The clinical success of these procedures relies strongly on the generation and sustainability of sufficient osseointegration around the implanted part during postoperative rehabilitation (e.g., progressive load bearing exercises) and daily activities (e.g., regular and challenging loads), respectively. ${ }^{[10,19]}$

\section{Prosthetic loading profile: Importance of characterization}

It is commonly accepted that osseointegration is, in part or in whole, achieved proportionally to the loading regimen transmitted to the implant by BAP overtime. ${ }^{[20-24]}$ Knowledge of the loading regimen is particularly critical for TTA fitted with BAP because the loading is directly translated from the ground to the implant via a single foot unit in contrast with tansfemoral BAP requiring an additional knee unit. ${ }^{[25-30]}$ An understanding of the loading regimen could be achieved through a so-called characterization of loading profile defined as a process of identifying and reporting specific loading variables prone to affect bone/implant interface. By definition, individual loading variables are affected by a combination of intrinsic factors associated with choice and alignment of foot and ankle units as well as extrinsic factors including the actual usage of the prosthesis during daily living, as illustrated in Figure $1 .^{[31]}$

Clearly, prosthetic feet fitted in transtibial BAP play a critical role in osseointegration in particular and clinical outcomes at large. ${ }^{[32,33]}$ They are the sole loading components fitted by prosthetists (e.g., choice, alignment) and subjected to cost-benefit analysis by funders (e.g., end-users, reimbursement bodies). ${ }^{[12]}$ The choice of this component is typically based on clinical experience of the prosthetist who considers altogether manufacturer's and provider's instructions, strength of osseointegration, functional outcomes, lifestyle and cost. ${ }^{[12,13,34,35]}$ Prosthetists could select a foot unit with a broad range of designs. Some are with or without anthropomorphic characteristics presenting a moment of resistance to dorsiflexion versus angle of dorsiflexion diagram with nonlinear convex and concave shape as defined in Pitkin et al (2010) and reported in previous studies, respectively. ${ }^{[36-42]}$

\section{Extraction of loading data: Limitations of fixed equipment}

One way to characterize the loading profile of transtibial BAP with a specific design is to rely on typical inverse dynamics equations providing comprehensive dynamics and kinematics information responsible for prosthetic and sound ankle, knee and hip joint kinetics. ${ }^{[4-50]}$ However, this approach requires fixed equipment placed in delimited space. Ground reaction forces and moments are collected using floor-mounted force-plates while linear and angular position of lower limb segments within a calibrated pre-set volume are captured using 3D motion analysis system. ${ }^{[43,44,51,52]}$ Instrumentation of walkways as well as stairs and ramps is possible but tedious and often costly. Number of steps considered is limited by the number of force-plates and cameras. The sole contact of each foot on a force-plate required for valid dynamic measurements is commonly achieved through personalized arrangement of the starting point and/or force-plates positioning to avoid targeting and/or repetitive recording of invalid trials. ${ }^{[43-}$ ${ }^{45]}$ Finally, inverse dynamics calculations are potentially sensitive to accurate extraction of inertial characteristics of prosthetic components. ${ }^{[53]}$ Altogether, the extraction of the loading profile using this approach is resource intensive and partially realistic.

\section{Portable kinetic system: Solution for ecological assessments}

Alternatively, loading profile of transtibial BAP fitted with a given foot can be characterized using direct kinetic measurements relying on portable tri-axial

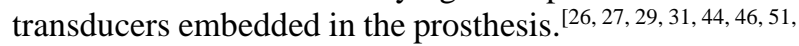
52, 54-70] This method has been used in previous studies involving case-series of TTAs fitted with socketsuspended prostheses that reported force versus moment in various planes during several walking activities (e.g., walking and turning round a circle) to compare prosthetic feet, determine the effect of anteroposterior alignment perturbations on rollover and predict intrasocket pressures. ${ }^{[25-27]}$

Previous direct measurements of loading applied on osseointegrated implants were also performed during rehabilitation program (e.g., static load bearing, use of walking aids), standardised (e.g., walking, ascending and descending stairs and ramps) and unscripted daily activities (e.g., open environment) as well as a fall but only for small cohorts of individuals fitted with transfemoral BAP. ${ }^{[31,44,51,52,58-70]}$ A singlecase study suggested ways to characterize the specific loading contribution of transfemoral BAP fitted with mechanical and microprocessor controlled knees units. $^{[31]}$

One of the typical limitations of these direct measurements was that explanations about the causes of the sole loading profile extracted were limited by the lack of complementary kinematic information. However, this method could allow prosthetic care providers to assess an unlimited number of steps and activities, making loading information extracted possibly somewhat more ecological and, therefore, more realistic. ${ }^{[59,60]}$

\section{Transtibial BAP loading: Need for characterization}

In summary, there is a body of literature demonstrating the benefits of using direct kinetic measurements to assess BAP loading but there is little evidence showing the ability these measurements to differentiate loading profile associated with particular components, let alone feet units. Information currently available can only partially assist in the development of comprehensive loading characterization of transtibial BAP capable to back up prosthetics fitting choices. One can logically assume that the methodological principles underlying the collect, analysis and reporting of loading profile laid out in studies focusing on transfemoral BAP 
should be fairly applicable to the characterization of loading applied on implant of TTAs fitted with BAP. However, this work is yet to be achieved.

Altogether, there is a need to establish a specific characterization of forces and moments applied on the three axes of osseointegrated implant of TTAs relying on state-of-the-art wireless compact tri-axial transducer capable to conduct ecological kinetic assessments of ambulation that is relevant to engineers, clinicians and biomechanists for better evidence-based design, fitting and assessments of transtibial BAP.

\section{Objectives}

The ultimate aim of this work was to improve the understanding of the actual daily loading regimen applied on osseointegrated implant of TTAs fitted with BAP.

The main purpose of this observational caseseries study was to present a comprehensive characterization of prosthetic loading profile susceptible to reflect the effect of various foot units on osseointegrated implant of three individuals with unilateral TTA during daily activities.

The specific objectives were:

1. To present the primary outcome corresponding to prosthetic loading data (i.e., three axial forces and moments) as well as secondary outcomes including a total of up to 390 variables comprising a set of three temporal characteristics, 36 loading boundaries, onset and magnitude of a maximum of 18 local extremum and three impulse variables for each of the five standardized daily activities (i.e., straight level walking, ascending and descending stairs and ramp) while fitted with instrumented BAPs, with a particular emphasis on variability.

2. To compare these prosthetic loading characteristics when participants were fitted with two instrumented BAPs each including load cell, their own connectors, pylon and footwear as well as (A) their usual foot units (i.e., RUSH, Trias, Triton) and (B) an anthropomorphic foot (i.e., Free-Flow Foot) using a set threshold to differentiate characteristics above minimum clinically important difference.

3. To suggest a comprehensive and specific, but yet transferable, characterization of loading profile of BAP fitted to TTAs build upon the extraction of variables the most sensitive to prosthetic feet.

\section{* Figure $1 *$}

\section{MATERIALS AND METHODS Participants}

This study involved all Queensland-based individuals with unilateral TTA fitted with a BAP using a so-called arm-length recruitment strategy applied by local prosthetists. No exclusion criteria were applied for gender, age, weight and height or level of activity. The specific inclusion criterion included (A) having circa six centimeters clearance between the percutaneous part of the implant and ankle joint to fit the load cell as well as
(B) being fully rehabilitated for at least 18 months, (C) capable to walk $200 \mathrm{~m}$ independently with BAP and (D) free of pain and infection at the time of recording. Human research ethics approval was received from the research institution. Written consent was obtained from all participants.

\section{Apparatus}

The load applied on the implant was measured while participants used two instrumented prostheses including their own usual (USU) and Free-Flow (FFF) foot successively. It should be highlighted that FFF developed by the Ohio Willow Wood has anthropomorphic design featuring a cam-rolling mechanism replicating resistance to dorsiflexion of concave shape seen in anatomical ankle. This is in a contrast with other prostheses with rigid ankles characterized as non-anthropomorphic. ${ }^{[37]}$

The instrumented prostheses included personal footwear, either USU or FFF foot, a pylon, a load cell attached with pyramidal adaptors and a connector clipped onto percutaneous part of press-fit osseointegrated implant (Figure 1).

A qualified prosthetist (CPO) with over 30 years of experience, including several years working with BAP, handled all aspects of prosthesis fitting.

The loading applied on the implant was measured using a tri-axial portable kinetic system (e.g., iPecsLab, RTC, US) set at $200 \mathrm{~Hz}$ including a load cell sending loading data wirelessly to a receiver connected to a laptop nearby. The three components of forces and moments were measured with previously established accuracy better than $1 \mathrm{~N}$ and $1 \mathrm{Nm}$, respectively. ${ }^{[31,49,58-}$ ${ }^{60]}$ The prosthetist aligned the coordinate system of load cell so that its vertical axis was co-axial with the long (LG) axis of the implant and the other axes corresponded to the anatomical anteroposterior (AP) and mediolateral (ML) directions of the implant (Figure 1). Forces acting along the AP, ML and $\mathrm{LG}$ axes were denoted as $\mathrm{F}_{\mathrm{AP}}$ (anterior was positive), $\mathrm{F}_{\mathrm{ML}}$ (lateral was positive), and $\mathrm{F}_{\mathrm{LG}}$ (compression was positive), respectively. Moments about the three axes were denoted as $\mathrm{M}_{\mathrm{AP}}$ (lateral rotation was positive), $\mathrm{M}_{\mathrm{ML}}$ (anterior rotation was positive) and $\mathrm{M}_{\mathrm{LG}}$ (external rotation was positive), respectively.

\section{Recording}

First, the prosthetist assembled the instrumented prosthesis with the load cell and selected foot as described above. Then, the prosthetists proceed to dynamic alignment of each prosthesis replicating as closely as possible to the bespoke participants' original alignment. Participants acclimated for approximately 15 min with prosthesis before assessment to ensure minimum confidence and comfort. Next, participants were asked to perform between three and five trials of five standardized daily activities including straight-line level walking (5 - $10 \mathrm{~m}$ walkway), ascending and descending ramp (2.5 m, $13.7 \mathrm{deg}$ incline) and stairs (3 stairs, $20 \mathrm{~cm}$ height, $24.5 \mathrm{~cm}$ deep, $100 \mathrm{~cm}$ wide) following protocol previously used for individuals with 
transfemoral amputation (Figure 1). ${ }^{[31,59,60]}$ Participants were instructed to complete each activity at a selfselected comfortable pace as well as to use handrails and take sufficient rest between trials to avoid fatigue if needed. Finally, the prosthesis was removed to allow load cell bench top calibration post recording with dynamic alignment (i.e., zero-offset).

\section{Processing}

The primary outcomes corresponding to the series of raw forces and moments were imported and processed in a customized Matlab software program (The MathWorks Inc., MA, USA) as detailed previously. ${ }^{[31,58-60,64,70]}$ The load data were offset according to the magnitude of the load recorded during calibration. The first and last strides recorded for each trial were removed to avoid considering gait initiation and termination, respectively. Heel contact and toe-off events were selected manually using $\mathrm{F}_{\mathrm{LG}}$. Datasets were time-normalized from 0 to 100 throughout the gait cycle (GC) or support phases (SUP) to facilitate averaging of trials and reporting of events and extremum in percentage of GC (\%GC) or SUP (\%SUP), respectively. Forces and moments for each gait cycle (GC) were normalized from 0 to 100 to facilitate averaging of trials and reporting of events in percentage of GC (\%GC). Forces and moments data were also expressed as percentage of bodyweight $(\% \mathrm{BW}$ and $\% \mathrm{BWm})$ to facilitate group averaging, respectively.

\section{Characterization}

The secondary outcomes constituting the basic characterization of a prosthetic foot loading involved up to 75 variables for a given activity or 390 variables for all activities, as represented in Figure 1, including a series of:

- Three spatio-temporal characteristics per activity including the cadence in strides per minute for a given trial as well as the duration of GC in seconds and the support phases in \%GC. These characteristics are surrogate measurements of the functional outcomes that can be readily compared with other symptomatic or able-bodied populations. ${ }^{[64]}$

- A total of 36 loading boundaries per activity corresponding to magnitude of minimum and maximum as well as the absolute maximum of the three components of forces expressed in $\% \mathrm{BW}$ and $\mathrm{N}$ as well as moments expressed in $\% \mathrm{BWm}$ and $\mathrm{Nm}$ for all gait cycles considered without consideration for the time of occurrence. This information is necessary to determine to which extent the actual loading applied relates to the loading tolerances of generic (e.g., foot) and specific (e.g., implant, connector, protective device) BAP components.

- Up to 18 loading local extremum per activity including up to three extremum for each of the three components of forces and moments as described previously. ${ }^{[31,58-61]}$ An extrema was defined as a point of inflection between loading slopes occurring consistently over successive GC for a given activity across all participants. Each extrema was detected semi-automatically by searching the maximum or minimum loading magnitude within a set time window selected manually. Extremum detected for each GC were described by a time of occurrence or onset expressed in percentage of support phase (\%SUP) as well as a magnitude normalized by bodyweight (\%BW or \% $\mathrm{BWm})$. Both onset and magnitude of extremum are necessary to develop subsequent automated pattern recognition of daily activities loading. Furthermore, particular discrete information at a point of time during the support phase (e.g., push off) extracted from continuous loading profile generated by a foot with unique design could be associated with regional osseointegration around implant. ${ }^{[21,22]}$

- $\quad$ Three impulse variables per activity expressed in $\%$ BWs were determined using conventional trapezoid method to integrate the area under of the three bodyweight normalized components of the force-time curves for each support phase. The impulse can be used as a clinical indicator reflecting the loading regimen that is useful to determine prosthesis usage and estimate components fatigue. ${ }^{[31,59,60]}$

\section{Comparative analysis}

Only the average and one standard deviation of each secondary outcome for a given prosthesis will be presented here. Supplement individual data will be presented in a subsequent a Data-in-Brief publication.

The variability of a dataset was determined using the percentage of variation ( $\mathrm{PV}=$ absolute [[standard deviation / mean] x100]). We considered that PV inferior or superior to $20 \%$ indicated a low and high variability, respectively.

The difference between feet for each of the secondary outcome was determined with FFF minus USU. Therefore, a positive and negative difference for a variable indicated that FFF was algebraically larger or smaller than USU, respectively. We determined whether differences are clinically meaningful by comparing it to a predetermined threshold. We considered that a difference superior and inferior to $10 \%$ was above and below a minimum clinically important difference (MCID), respectively. This threshold could appear low compared to other studies comparing prosthetic knee units suggesting that an MCID of $20 \%$ might be relevant. ${ }^{[71]}$ We believe a lower threshold is justified in the particular case of individuals with TTAs fitted with BAP given their increase proprioception due to osseoperception provided by osseointegrated implant. ${ }^{[72]}$ A lower threshold also contributed to a more conservative appraisal of differences in loading profiles between feet and discrimination of most sensitive variables.

\section{RESULTS}

The demographic, amputation and prosthetic 
information for the two males and one female who participated in study between May and July 2017 were summarized in Table 1. The usual prostheses included a RUSH foot (RUSH, US) and running shoes, Trias 1C30 (Otto Bock, US) and running shoes as well as Triton Vertical shock 1C6 (Otto Bock, US) for Participants 1, 2 and 3, respectively. Only P2 used a foot recommended for transfemoral BAP prostheses fitted to screw-type fixation. ${ }^{[73]}$ Their surgical procedure creating the direct skeletal attachment involved a total knee replacement and implantation of press-fit osseointegrated implant. ${ }^{[15]}$ All participants were active with an overall fairly high ambulatory capacity.

$$
\text { * Table } 1 *
$$

A total of 319 GCs were analysed, including 150 and 169 with USU and FFF feet, respectively. An overview of the mean and standard deviation pattern of the load applied on implant fitted with both feet during the support phase of walking, ascending and descending ramp and stairs are presented in Figures 2, 3, 4, 5 and 6, respectively. The characterization of the loading profile applied with each foot involved comparing 100 variables as detailed below.

\section{* Figure 2, Figure 3, Figure 4, Figure 5, Figure $6 *$}

\section{Spatio-temporal characteristics}

As presented in Table 2, 11 (73\%) and $13(87 \%)$ out of the 15 spatio-temporal characteristics considered for all activities showed a low variability with the USU and FFF feet, respectively. Only 3 (20\%) characteristics were above MCID including the duration of GC during ascending ramp and both stairs activities.

\section{$*$ Table $2 *$}

\section{Loading boundaries}

As detailed in Table 3, the loading boundaries across all participants and activities ranged between -20 $\% \mathrm{BW}$ and $48 \% \mathrm{BW}$ or $-215 \mathrm{~N}$ and $451 \mathrm{~N}$ on $\mathrm{F}_{\mathrm{AP}},-9$ $\% \mathrm{BW}$ and $17 \% \mathrm{BW}$ or $-75 \mathrm{~N}$ and $179 \mathrm{~N}$ on $\mathrm{F}_{\mathrm{ML}},-24$ $\% \mathrm{BW}$ and $112 \% \mathrm{BW}$ or $-252 \mathrm{~N}$ and $1,179 \mathrm{~N}$ on $\mathrm{F}_{\mathrm{LG}},-2$ $\% \mathrm{BWm}$ and $1 \% \mathrm{BWm}$ or $-24 \mathrm{Nm}$ and $11 \mathrm{Nm}$ on $\mathrm{M}_{\mathrm{AP}}$, $4 \% \mathrm{BWm}$ and $13 \% \mathrm{BWm}$ or $-45 \mathrm{Nm}$ and $141 \mathrm{Nm}$ on $\mathrm{M}_{\mathrm{ML}},-1 \% \mathrm{BWm}$ and $1 \% \mathrm{BWm}$ or $-9 \mathrm{Nm}$ and $13 \mathrm{Nm}$ on $\mathrm{M}_{\mathrm{LG}}$. The largest difference in loading between both feet across all axis and activities were $17 \% \mathrm{BW}$ and 155.67 $\mathrm{N}$ for forces as well as $3 \% \mathrm{BWm}$ and $38.08 \mathrm{Nm}$ for the moments.

\section{* Table $3 *$}

\section{Local extremum}

A total of 34 out of 90 potential local extremum across all activities were extracted as they occurred consistently for all participants (i.e., $\mathrm{F}_{\mathrm{AP} 1}, \mathrm{~F}_{\mathrm{AP} 2}, \mathrm{~F}_{\mathrm{ML} 1}$, $\mathrm{F}_{\mathrm{LG} 1}, \mathrm{M}_{\mathrm{AP} 1}, \mathrm{M}_{\mathrm{ML} 1}, \mathrm{M}_{\mathrm{ML} 2}, \mathrm{M}_{\mathrm{LG} 1}, \mathrm{M}_{\mathrm{LG} 2}$ ), including seven for the level walking, ascending and descending ramps as well as eight and five for ascending and descending stairs, respectively.

Onsets presented in Table 4 showed low variability for $11(32 \%)$ and $8(24 \%)$ extremum with USU and FFF feet, respectively. The difference of onset was above MCID for 15 (44\%) extremum including 3 (9\%), 4 (12\%), $3(9 \%), 4(12 \%)$ and $1(3 \%)$ during walking, ascending and descending ramp and stairs, respectively.

Magnitudes presented in Table 5 showed low variability for $8(24 \%)$ and $7(21 \%)$ extremum with USU and FFF feet, respectively. The difference of magnitude was above MCID for 16 (47\%) extremum including 3 (9\%), 4 (12\%), $3(9 \%), 4(12 \%)$ and $1(3 \%)$ during walking, ascending and descending ramp and stairs, respectively. The loading with FFF increased above MCID for $\mathrm{F}_{\mathrm{AP} 1}, \mathrm{M}_{\mathrm{AP} 1}$ and $\mathrm{M}_{\mathrm{ML} 1}$ during walking, $\mathrm{F}_{\mathrm{AP} 2}$ and $\mathrm{M}_{\mathrm{ML} 1}$ during ascending ramp, $\mathrm{F}_{\mathrm{AP} 2}, \mathrm{M}_{\mathrm{AP} 1}, \mathrm{M}_{\mathrm{ML} 1}$ and $\mathrm{M}_{\mathrm{LG} 1}$ during descending ramp as well as $\mathrm{F}_{\mathrm{AP} 2}$ during descending stairs. The loading with FFF decreased above MCID for $\mathrm{M}_{\mathrm{AP} 1}$ and $\mathrm{M}_{\mathrm{ML} 2}$ during ascending ramp, $\mathrm{M}_{\mathrm{ML} 2}$ during descending ramp, $\mathrm{F}_{\mathrm{ML} 1}, \mathrm{M}_{\mathrm{ML} 1}, \mathrm{M}_{\mathrm{ML} 2}, \mathrm{M}_{\mathrm{LG} 1}$ during ascending stairs as well as $\mathrm{M}_{\mathrm{AP} 1}$ during descending stairs.

\section{* Table 4, Table 5*}

\section{Impulse}

As presented in Table 6, $2(13 \%)$ and $3(20 \%)$ out of the 15 impulse variables considered for all activities showed a low variability for the USU and FFF feet, respectively. A total of $7(47 \%)$ variables were above MCID including increase and decrease of $\mathrm{I}_{\mathrm{AP}}$ during ascending and descending ramp, decrease of $\mathrm{I}_{\mathrm{ML}}$ during ramps and stairs activities and decrease of $\mathrm{I}_{\mathrm{LG}}$ during ascending stairs, respectively.

\section{* Table $6 *$}

\section{DISCUSSION \\ Outcomes}

Firstly, this study provided some information about the loading profile applied on implant by transtibial BAP fitted with two types of prosthetic feet (e.g., variability, differences).

The variability of the secondary outcomes with either foot followed a trend previously demonstrated for transfemoral BAP showing low variability in spatiotemporal characteristics and high variability in both onset and magnitude of local extremum and impulse. ${ }^{[31 \text {, }}$ $59,60,64]$ The variability in onset and magnitude of extremum seemed to be higher during walking and stairs activities, as well as descending ramp with FFF compared to USU, respectively. However, the variability in impulse was similar for both feet but lower with FFF during ascending stairs.

The magnitude of the load using either foot was also within an expected range based on previous direct measurements of loading applied on implant of transfemoral BAP. The loading boundaries were 
comparable for both feet in all activities. Participants applied up to $48 \% \mathrm{BW}, 17 \% \mathrm{BW}$ and $112 \% \mathrm{BW}$ on the $\mathrm{F}_{\mathrm{AP}}, \mathrm{F}_{\mathrm{ML}}$ and $\mathrm{F}_{\mathrm{LG}}$, as well as $2.20 \% \mathrm{BWm}, 13.17 \% \mathrm{BWm}$ and $1.19 \% \mathrm{BWm}$ around the $\mathrm{M}_{\mathrm{AP}}, \mathrm{M}_{\mathrm{ML}}$ and $\mathrm{M}_{\mathrm{LG}}$ of the implant.

Interestingly, the differences in onset and magnitude of extremum between feet appeared inconsistently decreased and/or increased below and/or above MCID across activities except for $\mathrm{L}_{\mathrm{LG} 1}, \mathrm{M}_{\mathrm{AP1}}$ and $\mathrm{M}_{\mathrm{ML1}}$. $\mathrm{L}_{\mathrm{LG} 1}$ was the only extrema consistently below MCID for all activities. $\mathrm{M}_{\mathrm{AP} 1}$ and $\mathrm{M}_{\mathrm{ML} 1}$ were the most frequently above MCID across all activities except for the onset during descending ramps and stairs and for the magnitude during ascending and descending stairs, respectively. The differences in impulse between feet was also inconsistently decreased and/or increased above and/or below MCID across activities.

Differences in loading extremum and impulse between USU and FFF can only be minimally attributed to spatial-temporal characteristics since the cadence and duration of the gait cycles were comparable for both feet while performing each activity. Therefore, these differences could be possibly explained by the combination of short acclimation with FFF and, more importantly, the specific mechanical contribution of specific feet inherent to non-anthropomorphic (USU) and anthropomorphic (FFF) designs.

Secondly, this study provided some insights into the creation of specific and comprehensive characterization of loading profile of prosthetic feet for transtibial BAP.

Results highlighted some limitations of visual observations and possibly basic assessments (e.g., podometers) of spatio-temporal characteristics alone as they were the least sensitive to differences in foot design. It is difficult to ascertain if an expert can visually discriminate differences in loading. Hence, these results confirmed the benefits for prosthetic care providers to rely on complementary direct loading measurements providing individualized insight into impact of components.

Furthermore, this study confirmed that a loading characterization could rely on portable tri-axial load cell for ecological, but standardized, assessment of daily activities as demonstrated previously. ${ }^{[31,51,58-60,64 \text {, }}$

${ }^{66]}$ Results showed that assessing straight level walking alone might only partially reflect the actual loading regimen applied on implant during daily life given that most maximum loading occurred during other activities, particularly ascending ramp. More practically, this study indicated that at least nine extremum (i.e., $\mathrm{F}_{\mathrm{AP} 1}, \mathrm{~F}_{\mathrm{AP} 2}$, $\mathrm{F}_{\mathrm{ML} 1}, \mathrm{M}_{\mathrm{AP} 1}, \mathrm{M}_{\mathrm{AP} 2}, \mathrm{M}_{\mathrm{ML} 1}, \mathrm{M}_{\mathrm{ML} 2}, \mathrm{M}_{\mathrm{LG} 1}$ and $\mathrm{M}_{\mathrm{LG} 2}$ ) might be sufficient to show not only the differences between feet constructs but also particular loading effects of a specific foot design.

\section{Limitations}

This study involved a limited number of participants but altogether representing $42 \%$ of existing population of TTA fitted with press-fit implant worldwide. The shortcomings in the recording of the loading data included the individualized positioning of the load cell in relation to the implant depending on individual length of residuum, the short staircase, the short acclimation time with FFF, the range of ankle units considered in the USU group and lack of blinding of components. $^{[33]}$ The analysis relied on educated choices of thresholds to appreciate low variability $(\mathrm{PV}<20 \%)$ and clinical differences (MCID<10\%). Furthermore, the interpretation was limited by the lack of assessment of confounders associated with spatial gait characteristics (e.g., walking base, step and stride length), as well as dynamics (e.g., ground and handrail reaction forces), kinematics (e.g., trunk bending, knee range of movement) and kinetics (e.g., prosthesis ankle stiffness, knees and hips joint power) information as well as participants' subjective feedback (e.g., comfort score).

\section{Generalization}

The generalization of loading data must be considered carefully giving the typical intrinsic shortcoming of a case-series study and limitations listed above. Nonetheless, this study provided initial benchmark of kinetic data of a small cohort but yet representative of current existing population of TTAs fitted with BAP. The difference in loading extremum showed between participants fitted with different feet confirmed both the benefits of individualized assessments when looking at loading effects of specific components and the need to consider participants fitted with homogenous component's design while conducting observational cohort studies, if possible.

More generalizable are the methodological contributions listed above for a comprehensive recording, analysis and reporting the prosthetic loading characteristics. Indeed, this information should be considered and, possibly, educate the design of subsequent studies focusing on characterization of kinetics data for TTA fitted with BAP (e.g., purchase of equipment, environment and duration of recording, software development for analysis). For example, proper consideration to the relevant number of extremum might reduce noticeably computing time, particularly when detected manually.

\section{Future studies}

The proposed characterization will facilitate future longitudinal studies comparing prostheses constructs (e.g., components, alignment, anthropomorphicity) for a larger cohort of individuals with TTA fitted with a BAP or even a socket-suspended prosthesis. This will provide further information and, eventually, a better understanding of intra- and intervariability between participants, attachments, components and activities.

Opportunities for cross-sectional studies are endless, particularly for the ones associating the proposed characterization with complementary mechanical (e.g., dynamics, kinematics, kinetics characteristics), physiological (e.g., electromyography 
of residuum muscles, metabolic energy consumption) and participant's experience (e.g., comfort score, MCID threshold) data. Establishing how prosthetic loading with different ankle stiffness profile participate in the development of osseointegration over time will be particularly valuable.

\section{CONCLUSIONS}

An attempt to develop a comprehensive characterization of loading profile of bone-anchored prosthesis fitted to individuals with transtibial amputation was shared for the first time. This work was an initial effort toward laying out characterization principles for kinetic analysis while providing initial benchmark of ecological loading data.

Altogether, this study should be considered as a stepping-stone for prosthetic care providers responsible for addressing the ever increasing demand for stronger evidence-based fitting of components to justify costbenefit of clinical decision-making and subsequent prescription choices for growing population of individuals fitted with transtibial osseointegrated implant worldwide.

\author{
ABREVIATIONS \\ \%BW: Percentage of body weight \\ $\% \mathrm{BWm}$ : Percentage of body weight per metre \\ $\%$ SUP: Percentage of support phase \\ AP: Anteroposterior axis of the implant \\ BAP: Bone-anchored prosthesis \\ BW: Body weight \\ $\mathrm{F}_{\mathrm{AP}}$ : Component of the force applied on the \\ anteroposterior axis of the implant \\ FFF: Free-Flow foot and ankle \\ $\mathrm{F}_{\mathrm{LG}}$ : Component of the force applied on the long axis of \\ the implant \\ $\mathrm{F}_{\mathrm{ML}}$ : Component of the force applied on the mediolateral \\ axis of the implant \\ GC: Gait cycle \\ $\mathrm{I}_{\mathrm{AP}}$ : Impulse of $\mathrm{F}_{\mathrm{AP}}$ \\ $\mathrm{I}_{\mathrm{LG}}$ : Impulse of $\mathrm{F}_{\mathrm{LG}}$ \\ $\mathrm{I}_{\mathrm{ML}}$ : Impulse of $\mathrm{F}_{\mathrm{ML}}$ \\ $\mathrm{I}_{\mathrm{RT}}$ : Impulse of $\mathrm{F}_{\mathrm{RT}}$ \\ LG: Long axis of the implant \\ $\mathrm{M}_{\mathrm{AP}}$ : Moment around the anteroposterior axis of the \\ implant \\ MCID: Minimum clinically important difference \\ ML: Mediolateral axis of the implant \\ $\mathrm{M}_{\mathrm{LG}}$ : Moment around the long axis of the implant \\ $\mathrm{M}_{\mathrm{ML}}$ : Moment around the mediolateral axis of the \\ implant \\ P: Participants (P1, P2, P3) \\ PV: Percentage of Variation \\ SUP: Support phasis of gait cycle \\ TTA: Individuals with transtibial amputation \\ USU: Participant's own "usual” prosthesis
}

\section{ACKNOWLEDGMENTS}

Funding for this work was provided in part by the
National Institute of Arthritis and Musculoskeletal and Skin Diseases of the National Institutes of Health under Award Number AR43290. The work solely conducted by Laurent Frossard focusing on the characterisation of the loading data related secondary outcomes (i.e., temporal characteristics, maximum loading, local extremum, impulse) was partially supported by the Office of the Assistant Secretary of Defense for Health Affairs, through the Orthotics and Prosthetics Outcomes Research Program - Prosthetics Outcomes Research Award under Award No. W81XWH-16-1-0475. Opinions, interpretations, conclusions and recommendations are those of the author and are not necessarily endorsed by the Department of Defense.

The authors wish to acknowledge Jim Colvin and the Ohio Willow Wood for providing the Free-Flow feet as well as Samantha Leech and Michele Mahoney from Barry Leech Prosthetics \& Orthotics Pty Ltd for their valuable contribution to the organisation of the data collection.

\section{TO KNOW MORE}
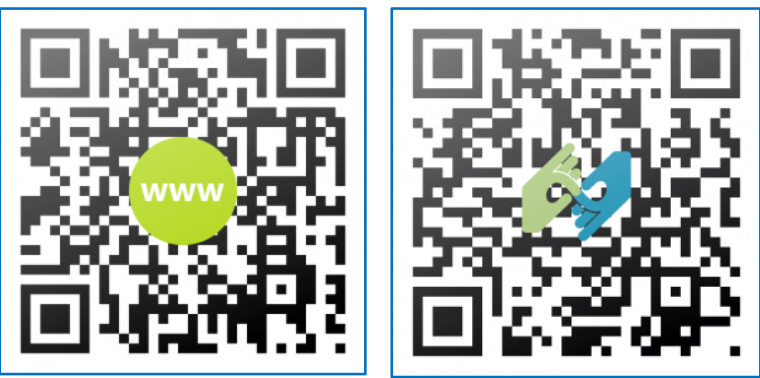

\section{REFERENCES}

1. Hebert, J.S., M. Rehani, and R. Stiegelmar, Osseointegration for Lower-Limb Amputation: A Systematic Review of Clinical Outcomes. JBJS Reviews, 2017. 5(10). p. e10.

2. Leijendekkers, R.A., G. van Hinte, J.P. Frolke, H. van de Meent, M.W. Nijhuis-van der Sanden, and J.B. Staal, Comparison of boneanchored prostheses and socket prostheses for patients with a lower extremity amputation: a systematic review. Disabil Rehabil, 2017. 39(11). p. 1045-1058.

3. van Eck, C.F. and R.L. McGough, Clinical outcome of osseointegrated prostheses for lower extremity amputations: a systematic review of the literature. Current Orthopaedic Practice, 2015. 26(4). p. 349-357.

4. Pitkin, M., Design features of implants for direct skeletal attachment of limb prostheses. J Biomed Mater Res A, 2013. 101(11). p. 3339 48.

5. Kunutsor, S.K., D. Gillatt, and A.W. Blom, Systematic review of the safety and efficacy of osseointegration prosthesis after limb amputation. BJS, 2018. 0(0).

6. Atallah, R., R.A. Leijendekkers, T.J. Hoogeboom, and J.P. Frolke, Complications of bone-anchored prostheses for individuals with 
an extremity amputation: A systematic review. PLoS One, 2018. 13(8). p. e0201821.

7. Nebergall, A., C. Bragdon, A. Antonellis, J. Karrholm, R. Branemark, and H. Malchau, Stable fixation of an osseointegated implant system for above-the-knee amputees: titel RSA and radiographic evaluation of migration and bone remodeling in 55 cases. Acta Orthop, 2012. 83(2). p. 121-8.

8. Tillander, J., K. Hagberg, L. Hagberg, and R. Branemark, Osseointegrated titanium implants for limb prostheses attachments: infectious complications. Clin Orthop Relat Res, 2010. 468(10). p. 2781-8.

9. Juhnke, D., J. Beck, S. Jeyapalina, and H. Aschoff, Fifteen years of experience with Integral-Leg-Prosthesis: Cohort study of artificial limb attachment system. Journal of Rehabilitation Research and Development, 2015. 52(4). p. 407-420.

10. Hagberg, K. and R. Branemark, One hundred patients treated with osseointegrated transfemoral amputation prostheses-rehabilitation perspective. J Rehabil Res Dev, 2009. 46(3). p. 331-44.

11. Frossard, L., L. Ferrada, T. Quincey, B. Burkett, and D. Berg, Development of a government continuous quality improvement procedure for assessing the provision of bone anchored limb prosthesis: A process re-design descriptive study. Canadian Prosthetics \& Orthotics Journal, 2018. 1(2). p. 1-14.

12. Frossard, L., D. Berg, G. Merlo, T. Quincey, and B. Burkett, Cost Comparison of SocketSuspended and Bone-Anchored Transfemoral Prostheses. Journal of Prosthetics and Orthotics, 2017. 29(4). p. 150-160.

13. Frossard, L.A., G. Merlo, B. Burkett, T. Quincey, and D. Berg, Cost-effectiveness of bone-anchored prostheses using osseointegrated fixation: Myth or reality? Prosthet Orthot Int, 2018. 42(3). p. 318-327.

14. Muderis, M.A., K. Tetsworth, A. Khemka, S. Wilmot, B. Bosley, S.J. Lord, and V. Glatt, The Osseointegration Group of Australia Accelerated Protocol (OGAAP-1) for two-stage osseointegrated reconstruction of amputated limbs. Bone Joint J, 2016. 98-B(7). p. 952-60.

15. Khemka, A., L. Frossard, S.J. Lord, B. Bosley, and M. Al Muderis, Osseointegrated total knee replacement connected to a lower limb prosthesis: 4 cases. Acta Orthop, 2015. p. 1-5.

16. Leijendekkers, R.A., G. van Hinte, J.P. Frolke, H. van de Meent, F. Atsma, M.W. Nijhuis-van der Sanden, and T.J. Hoogeboom, Functional performance and safety of bone-anchored prostheses in persons with a transfemoral or transtibial amputation: a prospective one-year follow-up cohort study. Clin Rehabil, 2018. p. 269215518815215.
17. Atallah, R., J.J. Li, W. Lu, R. Leijendekkers, J.P. Frolke, and M. Al Muderis, Osseointegrated Transtibial Implants in Patients with Peripheral Vascular Disease: A Multicenter Case Series of 5 Patients with 1Year Follow-up. J Bone Joint Surg Am, 2017. 99(18). p. 1516-1523.

18. Uglow, M. and K.F. Fitzpatrick, The Osseointegration Group of Australia Accelerated Protocol (OGAAP-1) for two-stage osseointegrated reconstruction of amputated limbs - Editorial. Bone Joint J, 2016. 98-B(7).

19. Aschoff, H.-H. and R. McGough, The EndoExo Femoral Prosthesis: a new rehabilitation concept following above knee amputation. Journal of Bone and Joint Surgery, British Volume, 2012. 94-B(SUPP XXXIX). p. 77.

20. Stenlund, P., M. Trobos, J. Lausmaa, R. Branemark, P. Thomsen, and A. Palmquist, Effect of load on the bone around boneanchored amputation prostheses. J Orthop Res, 2017. 35(5). p. 1113-1122.

21. Helgason, B., H. Palsson, T.P. Runarsson, L. Frossard, and M. Viceconti, Risk of failure during gait for direct skeletal attachment of a femoral prosthesis: a finite element study. Med Eng Phys, 2009. 31(5). p. 595-600.

22. Lee, W.C., J.M. Doocey, R. Branemark, C.J. Adam, J.H. Evans, M.J. Pearcy, and L.A. Frossard, FE stress analysis of the interface between the bone and an osseointegrated implant for amputees--implications to refine the rehabilitation program. Clin Biomech (Bristol, Avon), 2008. 23(10). p. 1243-50.

23. Prochor, P., Finite element analysis of stresses generated in cortical bone during implantation of a novel Limb Prosthesis Osseointegrated Fixation System. Biocybernetics and Biomedical Engineering, 2017.

24. Prochor, P. and E. Sajewicz, A comparative analysis of internal bone remodelling concepts in a novel implant for direct skeletal attachment of limb prosthesis evaluation: A finite element analysis. Proc Inst Mech Eng H, 2018. p. 954411917751003.

25. Neumann, E.S., K. Yalamanchili, J. Brink, and J.S. Lee, Transducer-based comparisons of the prosthetic feet used by transtibial amputees for different walking activities: a pilot study. Prosthet Orthot Int, 2012. 36(2). p. 203-16.

26. Neumann, E.S., J. Brink, K. Yalamanchili, and J.S. Lee, Use of a Load Cell and Force-Moment Analysis to Examine Transtibial Prosthesis Foot Rollover Kinetics for Anterior-Posterior Alignment Perturbations. JPO Journal of Prosthetics and Orthotics, 2012. 24(4). p. 160174.

27. Neumann, E.S., J. Brink, K. Yalamanchili, and J.S. Lee, Regression Estimates of Pressure on Transtibial Residual Limbs Using Load Cell 
Measurements of the Forces and Moments Occurring at the Base of the Socket. JPO Journal of Prosthetics and Orthotics, 2013. 25(1). p. 1-12.

28. Kobayashi, T., M.S. Orendurff, M. Zhang, and D.A. Boone, Effect of transtibial prosthesis alignment changes on out-of-plane socket reaction moments during walking in amputees. J Biomech, 2012. 45(15). p. 2603-9.

29. Boone, D.A., T. Kobayashi, T.G. Chou, A.K. Arabian, K.L. Coleman, M.S. Orendurff, and M. Zhang, Influence of malalignment on socket reaction moments during gait in amputees with transtibial prostheses. Gait Posture, 2013. 37(4). p. 620-6.

30. Kobayashi, T., M.S. Orendurff, M. Zhang, and D.A. Boone, Effect of alignment changes on sagittal and coronal socket reaction moment interactions in transtibial prostheses. $\mathbf{J}$ Biomech, 2013. 46(7). p. 1343-50.

31. Frossard, L., E. Haggstrom, K. Hagberg, and P. Branemark, Load applied on a bone-anchored transfemoral prosthesis: characterisation of prosthetic components - A case study Journal of Rehabilitation Research \& Development, 2013. 50(5). p. 619-634.

32. Samuelsson, K.A., O. Toytari, A.L. Salminen, and A. Brandt, Effects of lower limb prosthesis on activity, participation, and quality of life: a systematic review. Prosthet Orthot Int, 2012. 36(2). p. 145-58.

33. Raschke, S.U., M.S. Orendurff, J.L. Mattie, D.E. Kenyon, O.Y. Jones, D. Moe, L. Winder, A.S. Wong, A. Moreno-Hernandez, M.J. Highsmith, J.S. D, and T. Kobayashi, Biomechanical characteristics, patient preference and activity level with different prosthetic feet: a randomized double blind trial with laboratory and community testing. J Biomech, 2015. 48(1). p. 146-52.

34. Haggstrom, E.E., E. Hansson, and K. Hagberg, Comparison of prosthetic costs and service between osseointegrated and conventional suspended transfemoral prostheses. Prosthet Orthot Int, 2013. 37(2). p. 152-60.

35. Hansson, E., K. Hagberg, M. Cawson, and T.H. Brodtkorb, Patients with unilateral transfemoral amputation treated with a percutaneous osseointegrated prosthesis - Cost effecteviness analysis. The Bone \& Joint Journal, 2018. 100B(4). p. 527-534.

36. Pitkin, M., Anthropomorphicity of lower limb prostheses, in Biomechanics of Lower Limb Prosthetics2010, Springer: Heidelberg, Dondrecht, London, New York. p. 7.

37. Pitkin, M.R., Synthesis of a cycloidal mechanism of the prosthetic ankle. Prosthet Orthot Int, 1996. 20(3). p. 159-71.
38. Pitkin, M.R., Effects of Design Variants in Lower-Limb Prostheses on Gait Synergy. J Prosthet Orthot, 1997. 9(3). p. 113-122.

39. Quesada, P.M., M. Pitkin, J. Colvin, and J. Hays, Comparative assessment of dynamic rotational stiffness of common and prototype foot/ankle prostheses during simulated stance. Advances in Bioengineering, 1998. 35. p. 317 318.

40. Pitkin, M., Optimization criterion for the moment in the rolling joint prosthetic foot. Journal of Biomechanics, 1998. 31. p. 163.

41. Pitkin, M., What can normal gait biomechanics teach a designer of lower limb prostheses? Acta of bioengineering and biomechanics / Wroclaw University of Technology, 2013. 15(1). p. 3-10.

42. Quesada, P.M., M. Pitkin, and J. Colvin, Biomechanical evaluation of a prototype foot/ankle prosthesis. IEEE Transactions on Rehabilitation Engineering, 2000. 8(1). p. 156159.

43. Frossard, L., L. Cheze, and R. Dumas, Dynamic input to determine hip joint moments, power and work on the prosthetic limb of transfemoral amputees: ground reaction vs knee reaction. Prosthet Orthot Int, 2011. 35(2). p. 140-9.

44. Dumas, R., R. Branemark, and L. Frossard, Gait analysis of transfemoral amputees: errors in inverse dynamics are substantial and depend on prosthetic design. IEEE Trans Neural Syst Rehabil Eng, 2017. 25(6). p. 679-685.

45. Dumas, R., L. Cheze, and L. Frossard, Loading applied on prosthetic knee of transfemoral amputee: comparison of inverse dynamics and direct measurements. Gait Posture, 2009. 30(4). p. 560-2.

46. Neumann, E., L. Frossard, M. Ramos, and K. Bidwell, Prosthesis: Load Cell Applicability to Outcome Measurement - Chapter 6, in Advances in Medicine and Biology, L.V. Berhardt, Editor 2017, Nova Science Publishers: New York. p. 133-172.

47. Stephenson, P. and B.B. Seedhom, Estimation of forces at the interface between an artificial limb and an implant directly fixed into the femur in above-knee amputees. Journal of Orthopaedic Science, 2002. 7(3). p. 192-297.

48. Dumas, R., L. Cheze, and L. Frossard, Load during prosthetic gait: Is direct measurement better than inverse dynamics? Gait \& Posture, 2009. 30(Supplement 2). p. S86-S87.

49. Koehler, S.R., Y.Y. Dhaher, and A.H. Hansen, Cross-validation of a portable, six-degree-offreedom load cell for use in lower-limb prosthetics research. J Biomech, 2014. 47(6). p. 1542-1547.

50. Thesleff, A., S. Ludvigsson, E. Ohr, and M. Ortiz-Catalan, Load exposure of osseointegrated implants for transfemoral limb 
prosthesis during running. Conf Proc IEEE Eng Med Biol Soc., 2018. p. 1743-1746.

51. Frossard, L., N. Stevenson, J. Sullivan, M. Uden, and M. Pearcy, Categorization of Activities of Daily Living of Lower Limb Amputees During Short-Term Use of a Portable Kinetic Recording System: A Preliminary Study. Journal of Prosthetics and Orthotics, 2011. 23(1). p. 2-11.

52. Frossard, L., N. Stevenson, J. Smeathers, E. Haggstrom, K. Hagberg, J. Sullivan, D. Ewins, D. Lee Gow, S. Gray, and R. Branemark, Monitoring of the load regime applied on the osseointegrated fixation of a trans-femoral amputee: a tool for evidence-based practice. Prosthet Orthot Int, 2008. 32(1). p. 68-78.

53. Futamure, S., V. Bonnet, R. Dumas, and G. Venture, A sensitivity analysis method for the body segment inertial parameters based on ground reaction and joint moment regressor matrices. Journal of Biomechanics, 2017.

54. Kobayashi, T., M.S. Orendurff, M. Zhang, and D.A. Boone, Socket reaction moments in transtibial prostheses during walking at clinically perceived optimal alignment. Prosthetics and Orthotics International, 2015.

55. Kobayashi, T., M.S. Orendurff, A.K. Arabian, T.G. Rosenbaum-Chou, and D.A. Boone, Effect of prosthetic alignment changes on socket reaction moment impulse during walking in transtibial amputees. J Biomech, 2014. 47(6). p. 1315-23.

56. Kobayashi, T., M.S. Orendurff, M. Zhang, and D.A. Boone, Individual responses to alignment perturbations in socket reaction moments while walking in transtibial prostheses. Clin Biomech (Bristol, Avon), 2014. 29. p. 590-594.

57. Kobayashi, T., A.K. Arabian, M.S. Orendurff, T.G. Rosenbaum-Chou, and D.A. Boone, Effect of alignment changes on socket reaction moments while walking in transtibial prostheses with energy storage and return feet. Clin Biomech (Bristol, Avon), 2014. 29(1). p. 47-56.

58. Frossard, L., J. Beck, M. Dillon, M. Chappell, and J.H. Evans, Development and preliminary testing of a device for the direct measurement of forces and moments in the prosthetic limb of transfemoral amputees during activities of daily living. Journal of Prosthetics and Orthotics, 2003. 15(4). p. 135-142.

59. Lee, W., L. Frossard, K. Hagberg, E. Haggstrom, and R. Brånemark, Kinetics analysis of transfemoral amputees fitted with osseointegrated fixation performing common activities of daily living. Clinical Biomechanics, 2007. 22(6). p. 665-673.

60. Lee, W., L. Frossard, K. Hagberg, E. Haggstrom, D. Lee Gow, S. Gray, and R. Branemark, Magnitude and variability of loading on the osseointegrated implant of transfemoral amputees during walking. Med Eng Phys, 2008. 30(7). p. 825-833.

61. Frossard, L., K. Hagberg, E. Haggstrom, and R. Branemark, Load-relief of walking aids on osseointegrated fixation: instrument for evidence-based practice. IEEE Trans Neural Syst Rehabil Eng, 2009. 17(1). p. 9-14.

62. Frossard, L., R. Tranberg, E. Haggstrom, M. Pearcy, and R. Branemark, Fall of a transfemoral amputee fitted with osseointegrated fixation: loading impact on residuum. Gait \& Posture, 2009. 30(Supplement 2). p. S151-S152.

63. Frossard, L., D.L. Gow, K. Hagberg, N. Cairns, B. Contoyannis, S. Gray, R. Branemark, and M. Pearcy, Apparatus for monitoring load bearing rehabilitation exercises of a transfemoral amputee fitted with an osseointegrated fixation: a proof-of-concept study. Gait Posture, 2010. 31(2). p. 223-8.

64. Frossard, L., K. Hagberg, E. Häggström, D.L. Gow, R. Brånemark, and M. Pearcy, Functional Outcome of Transfemoral Amputees Fitted With an Osseointegrated Fixation: Temporal Gait Characteristics. Journal of Prosthetics and Orthotics, 2010. 22(1). p. 11-20.

65. Frossard, L.A., Load on osseointegrated fixation of a transfemoral amputee during a fall: Determination of the time and duration of descent. Prosthet Orthot Int, 2010. 34(4). p. 472-87.

66. Frossard, L.A., R. Tranberg, E. Haggstrom, M. Pearcy, and R. Branemark, Load on osseointegrated fixation of a transfemoral amputee during a fall: loading, descent, impact and recovery analysis. Prosthet Orthot Int, 2010. 34(1). p. 85-97.

67. Vertriest, S., P. Coorevits, K. Hagberg, R. Branemark, E. Haggstrom, G. Vanderstraeten, and L. Frossard, Static load bearing exercises of individuals with transfemoral amputation fitted with an osseointegrated implant: reliability of kinetic data. IEEE Trans Neural Syst Rehabil Eng, 2015. 23(3). p. 423-30.

68. Vertriest, S., P. Coorevits, K. Hagberg, R. Branemark, E.E. Haggstrom, G. Vanderstraeten, and L.A. Frossard, Static load bearing exercises of individuals with transfemoral amputation fitted with an osseointegrated implant: Loading compliance. Prosthet Orthot Int, 2017. 41(4). p. 393-401.

69. Vertriest, S., S. Pather, P. Sondergeld, and L. Frossard, Rehabilitation programs after the implantation of transfemoral osseointegrated fixations for bone-anchored prostheses: a scoping review protocol. JBI Database of Systematic Reviews and Implementation Reports, 2017. 15(2). p. 1-13. 
70. Pather, S., S. Vertriest, P. Sondergeld, M.A. Ramis, and L. Frossard, Load characteristics following transfemoral amputation in individuals fitted with bone-anchored prostheses: a scoping review protocol. JBI Database System Rev Implement Rep, 2018. 16(6). p. 1286-1310.

71. Orendurff, M.S., Literature Review of Published Research Investigating Microprocessor-Controlled Prosthetic Knees: 2010 - 2012. JPO: Journal of Prosthetics and Orthotics, 2013. 25(4S).

72. Haggstrom, E., K. Hagberg, B. Rydevik, and R. Branemark, Vibrotactile evaluation: osseointegrated versus socket-suspended transfemoral prostheses. J Rehabil Res Dev, 2013. 50(10). p. 1423-34.

73. OPRA Implant System Instructions for Use https://www.accessdata.fda.gov/cdrh_docs/pdf 8/H080004D.pdf, 2016. 
Figure 1. Overview of list of spatio-temporal characteristics, loading boundaries (e.g., minimum, maximum, absolute maximum), local extremum (e.g., onset, magnitude) and impulse variables considered to characterize prosthetic loading regimen depending on the combination of intrinsic factors including instrumented boneanchored prosthesis fitted with usual (USU) and Free-Flow (FFF) feet and extrinsic factors related to usage during standardized daily activity for Participant 3.

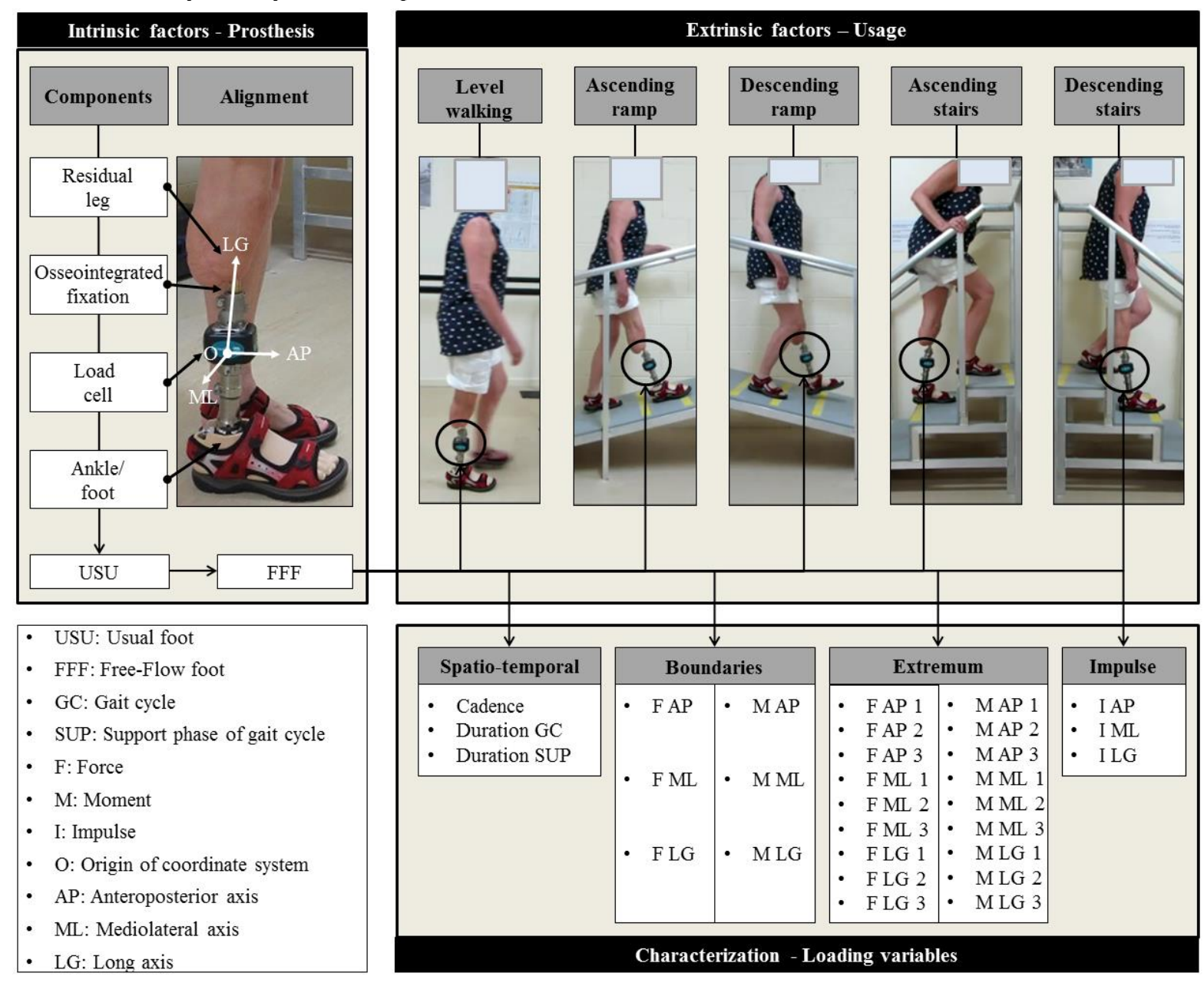


Figure 2. Mean and standard deviation of the load applied on osseointegrated implant by bone-anchored prosthesis fitted with usual (USU) and Free-Flow (FFF) feet during the support phase of walking.
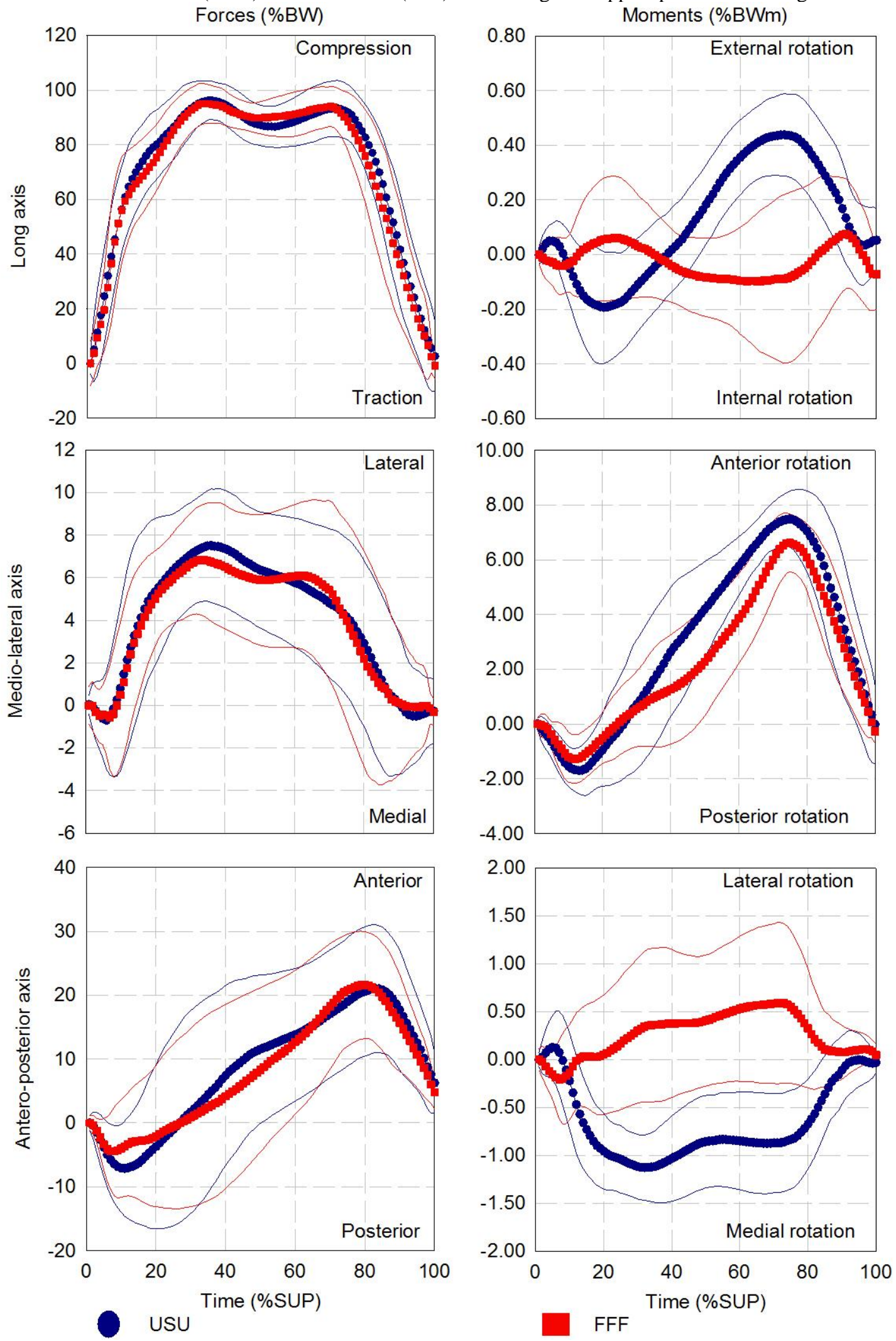
Figure 3. Mean and standard deviation of the load applied on osseointegrated implant by bone-anchored prosthesis fitted with usual (USU) and Free-Flow (FFF) feet during the support phase of ascending ramp.
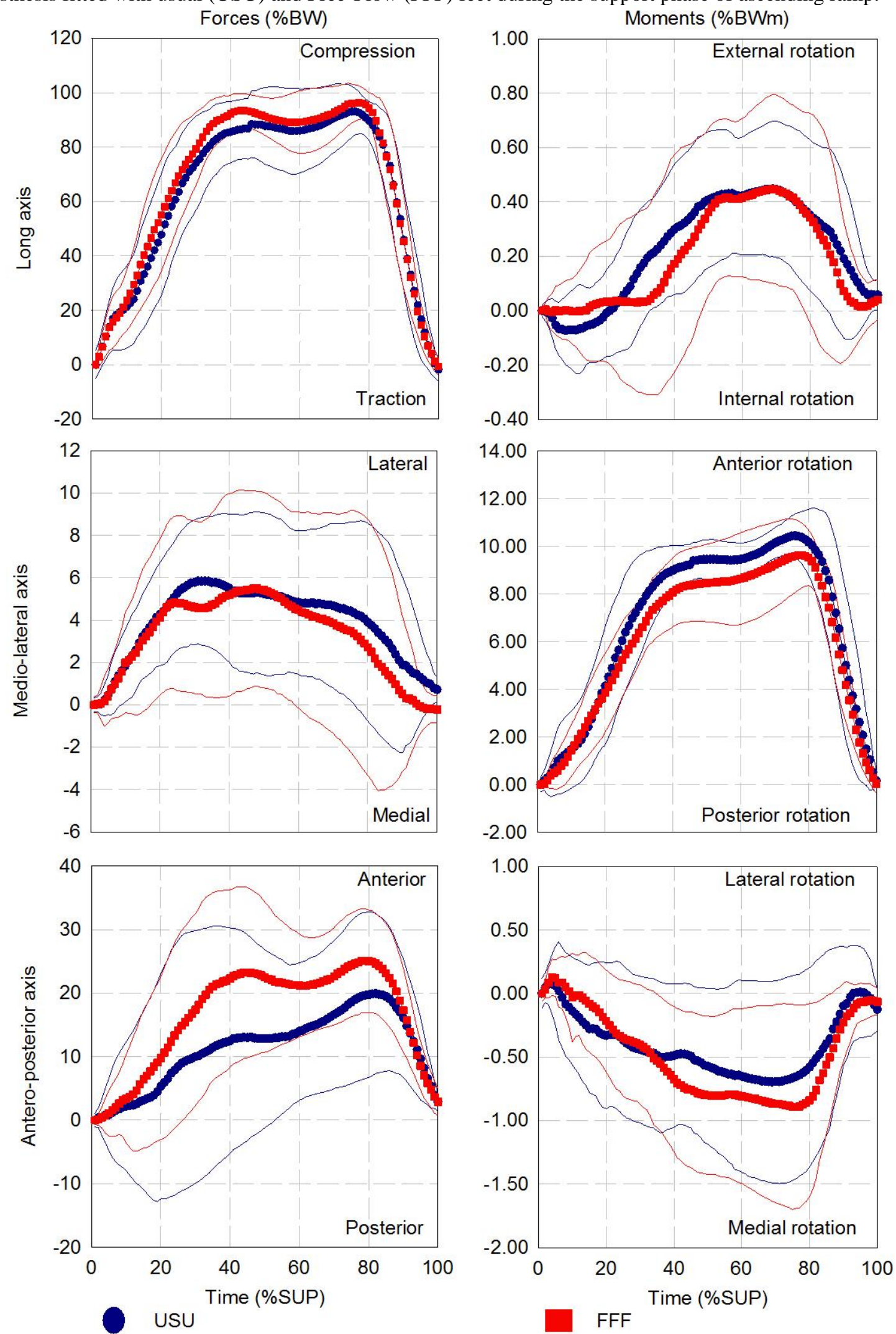
Figure 4. Mean and standard deviation of the load applied on osseointegrated implant by bone-anchored prosthesis fitted with usual (USU) and Free-Flow (FFF) feet during the support phase of descending ramp.
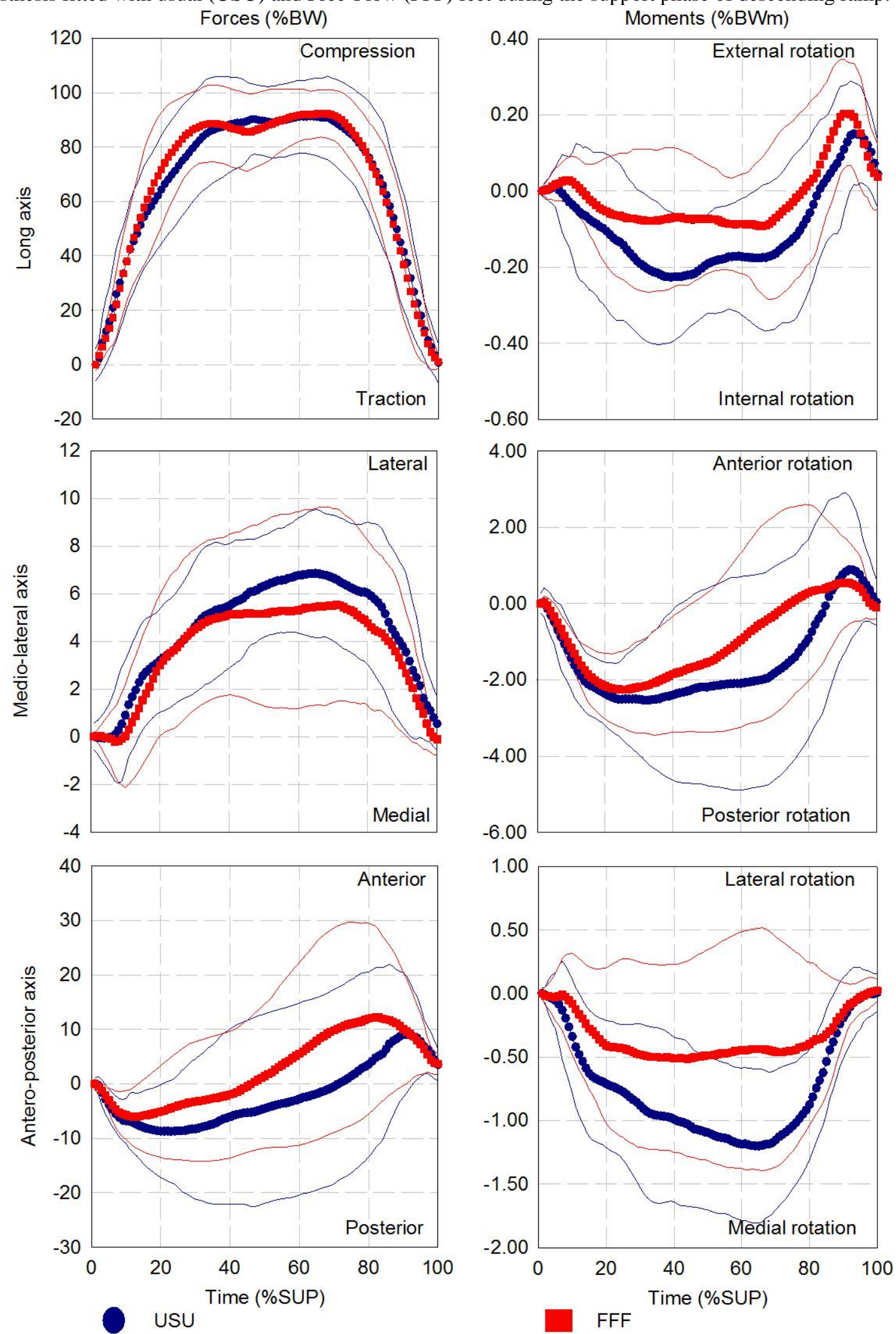
Figure 5. Mean and standard deviation of the load applied on osseointegrated implant by bone-anchored prosthesis fitted usual (USU) and Free-Flow (FFF) feet during the support phase of ascending stairs.
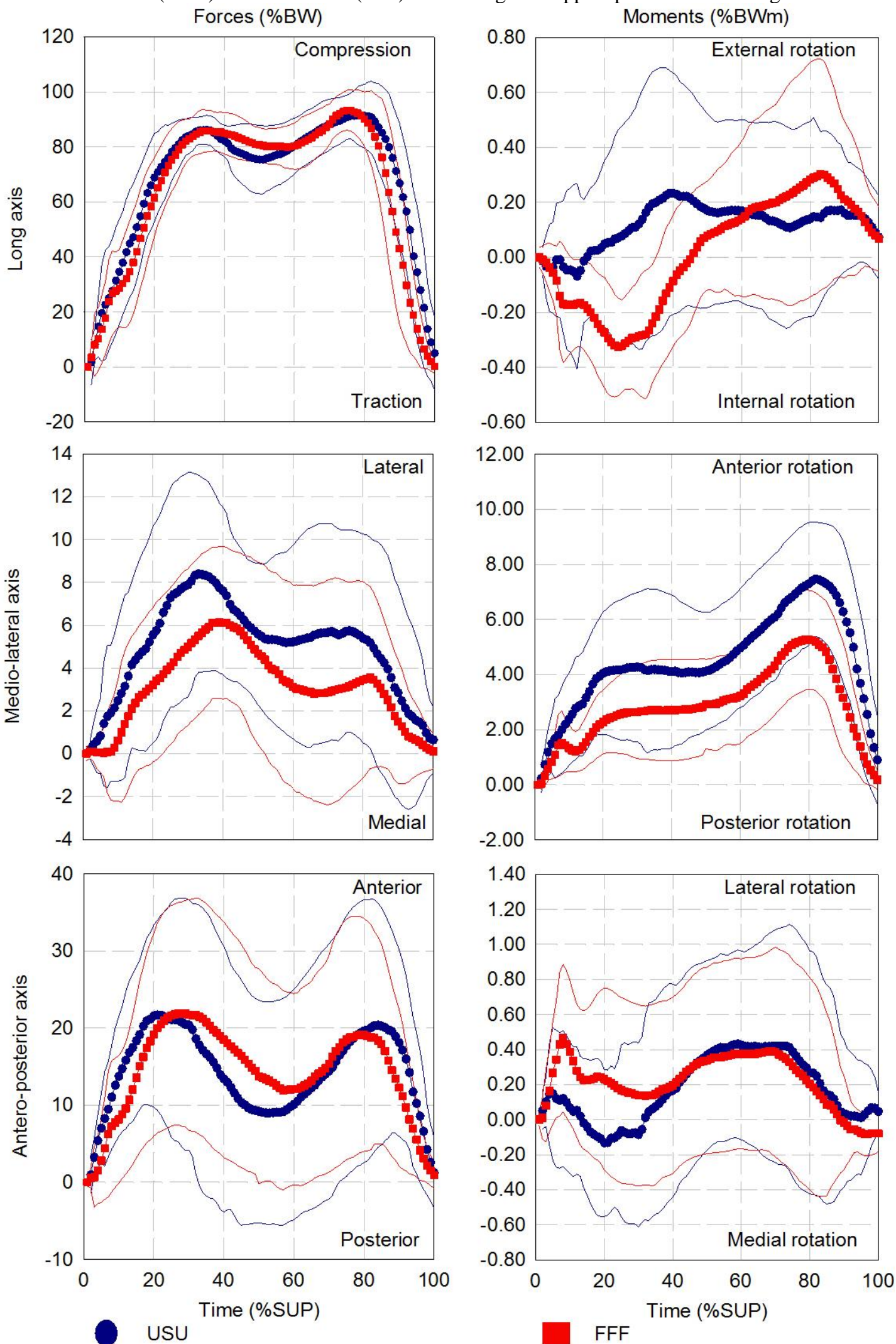
Figure 6. Mean and standard deviation of the load applied on osseointegrated implant by bone-anchored prosthesis fitted usual (USU) and Free-Flow (FFF) feet during the support phase of descending stairs
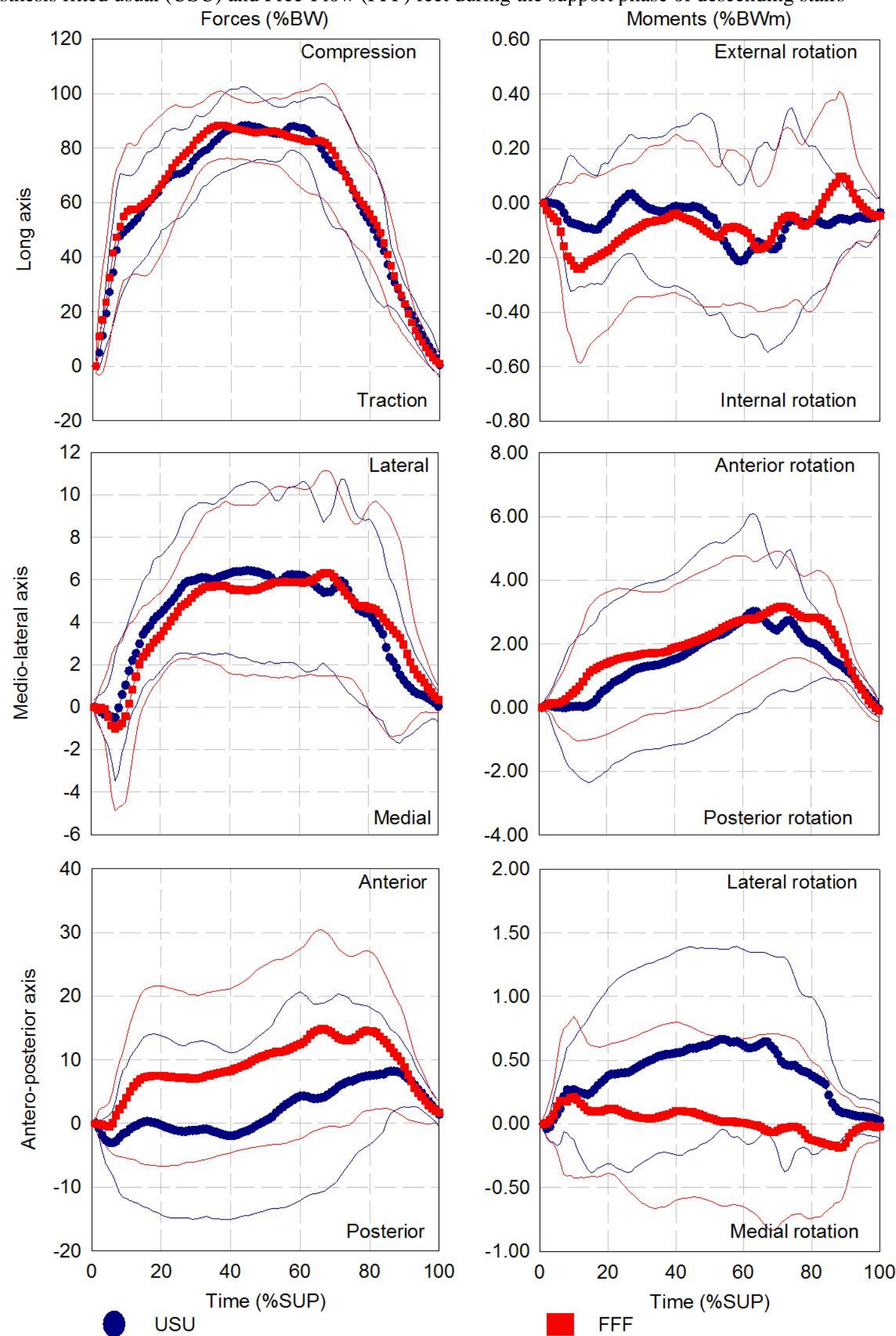
Table 1. Individual (P1, P2, P3) and grouped (All) demographics and amputation information as well as components of the usual prosthesis. M: Male, F: Female, L: Left, R: Right, OI: osseointegration, \%LoL: percentage of length of sound leg.

\begin{tabular}{|c|c|c|c|c|c|c|}
\hline & \multicolumn{3}{|c|}{ Participants } & \multicolumn{2}{|c|}{ All } \\
\hline & & P1 & $\mathbf{P 2}$ & P3 & Mean & SD \\
\hline \multicolumn{7}{|l|}{ Demographics } \\
\hline Gender & $(\mathrm{M} / \mathrm{F})$ & M & M & $\mathrm{F}$ & - & - \\
\hline Age & (Yrs) & 38 & 69 & 67 & 58 & 17 \\
\hline Height & (m) & 1.92 & 1.78 & 1.58 & 1.76 & 0.17 \\
\hline Mass & $(\mathrm{kg})$ & 109.12 & 81.74 & 59.52 & 83.46 & 24.84 \\
\hline BMI & $(\mathrm{kg} / \mathrm{m} 2)$ & 29.080 & 25.123 & 23.293 & 25.832 & 2.958 \\
\hline \multicolumn{7}{|l|}{ Amputation } \\
\hline Cause & & Other & Trauma & Trauma & - & - \\
\hline Side & (L/R) & $\mathrm{R}$ & $\mathrm{R}$ & $\mathrm{L}$ & - & - \\
\hline Time since amputatior & (Yrs) & 9 & 5 & 32 & 15 & 15 \\
\hline Time since OI & (Yrs) & 2 & 2 & 3 & 2 & 1 \\
\hline Length of leg & $(\mathrm{cm})$ & 46.94 & 42.67 & 37.28 & 42.30 & 4.84 \\
\hline Length of residuum & $(\mathrm{cm})$ & 12.42 & 9.38 & 11.52 & 11.11 & 1.56 \\
\hline Length of residuum & $(\% \mathrm{LoL})$ & 26.46 & 21.98 & 30.90 & 26.45 & 4.46 \\
\hline \multicolumn{7}{|l|}{ Usual prosthesis } \\
\hline Brand & & RUSH & Otto Bock & Otto Bock & - & - \\
\hline Model & & RUSH foot & Trias & Triton & - & - \\
\hline Footwear & & Running shoes & Running shoes & Sandals & - & - \\
\hline
\end{tabular}

Table 2. Mean and standard deviation of spatio-temporal characteristics including cadence, duration of gait cycle (GC) and support phasis while using usual (USU) and Free-Flow (FFF) feet during activities of daily living. H: High PV, L: Low PV, A: Above MCID, B: Below MCID.

\begin{tabular}{|c|c|c|c|c|c|c|c|c|c|c|c|}
\hline \multirow[b]{2}{*}{ USU } & \multirow[b]{3}{*}{ (Strides/min) } & \multicolumn{2}{|l|}{$\begin{array}{c}\text { Level } \\
\text { walking }\end{array}$} & \multicolumn{2}{|c|}{$\begin{array}{l}\text { Ascending } \\
\text { ramp }\end{array}$} & \multicolumn{2}{|c|}{$\begin{array}{l}\text { Descending } \\
\text { ramp }\end{array}$} & \multicolumn{2}{|c|}{$\begin{array}{c}\text { Ascending } \\
\text { stairs }\end{array}$} & \multicolumn{2}{|c|}{$\begin{array}{c}\text { Descending } \\
\text { stairs } \\
\end{array}$} \\
\hline & & & & & & & & & & & \\
\hline Cadence & & $50 \pm 7$ & $\mathrm{~L}$ & $40 \pm 10$ & $\mathrm{H}$ & $47 \pm 4$ & $\mathrm{~L}$ & $34 \pm 9$ & $\mathrm{H}$ & $19 \pm 4$ & $\mathrm{H}$ \\
\hline Gait cycle & (s) & $1.24 \pm 0.13$ & $\mathrm{~L}$ & $1.77 \pm 0.32$ & $\mathrm{~L}$ & $1.31 \pm 0.13$ & $\mathrm{~L}$ & $1.94 \pm 0.44$ & $\mathrm{H}$ & $1.78 \pm 0.32$ & $\mathrm{~L}$ \\
\hline Support & $(\% \mathrm{GC})$ & $64 \pm 3$ & $\mathrm{~L}$ & $66 \pm 4$ & $\mathrm{~L}$ & $65 \pm 5$ & $\mathrm{~L}$ & $59 \pm 3$ & $\mathrm{~L}$ & $65 \pm 6$ & $\mathrm{~L}$ \\
\hline \multicolumn{12}{|l|}{ FFF } \\
\hline Cadence & (Strides/min) & $49 \pm 6$ & $\mathrm{~L}$ & $39 \pm 7$ & $\mathrm{~L}$ & $48 \pm 5$ & $\mathrm{~L}$ & $34 \pm 9$ & $\mathrm{H}$ & $20 \pm 3$ & $\mathrm{~L}$ \\
\hline Gait cycle & (s) & $1.30 \pm 0.13$ & $\mathrm{~L}$ & $1.59 \pm 0.25$ & $\mathrm{~L}$ & $1.26 \pm 0.13$ & $\mathrm{~L}$ & $1.70 \pm 0.43$ & $\mathrm{H}$ & $1.54 \pm 0.26$ & $\mathrm{~L}$ \\
\hline Support & $(\% \mathrm{GC})$ & $64 \pm 3$ & $\mathrm{~L}$ & $65 \pm 4$ & $\mathrm{~L}$ & $62 \pm 3$ & $\mathrm{~L}$ & $59 \pm 8$ & $\mathrm{~L}$ & $63 \pm 5$ & $\mathrm{~L}$ \\
\hline \multicolumn{12}{|l|}{ Difference } \\
\hline Cadence & (Strides/min) & -1 & B & -1 & B & 1 & B & 1 & B & 1 & B \\
\hline Gait cycle & (s) & 0.059 & B & -0.181 & A & -0.049 & B & -0.239 & $\mathrm{~A}$ & -0.237 & A \\
\hline Support & $(\% \mathrm{GC})$ & 0 & B & -1 & B & -3 & B & 0 & B & -2 & B \\
\hline
\end{tabular}


Table 3. Loading boundaries including minimum (Min) and maximum (Max) magnitude of forces (F) expressed in \% BW and $\mathrm{N}$, and moments (M) expressed in \% BWm and $\mathrm{Nm}$, on the anteroposterior (AP), mediolateral (ML) and long (LG) axes of the implant fitted with usual (USU) and Free-Flow (FFF) feet during activities of daily living.

\begin{tabular}{|c|c|c|c|c|c|c|c|c|c|c|c|}
\hline & & \multicolumn{2}{|c|}{$\begin{array}{c}\text { Level } \\
\text { walking }\end{array}$} & \multicolumn{2}{|c|}{$\begin{array}{l}\text { Ascending } \\
\text { ramp }\end{array}$} & \multicolumn{2}{|c|}{$\begin{array}{l}\text { Descending } \\
\text { ramp }\end{array}$} & \multicolumn{2}{|c|}{$\begin{array}{l}\text { Ascending } \\
\text { stairs }\end{array}$} & \multicolumn{2}{|c|}{$\begin{array}{l}\text { Descending } \\
\text { stairs }\end{array}$} \\
\hline & & Min & $\operatorname{Max}$ & Min & Max & Min & Max & Min & Max & Min & Max \\
\hline \multicolumn{12}{|l|}{ USU } \\
\hline $\mathrm{F}_{\mathrm{AP}}$ & $(\% \mathrm{BW})$ & -16 & 39 & -12 & 40 & -20 & 48 & -15 & 42 & -17 & 33 \\
\hline $\mathrm{F}_{\mathrm{ML}}$ & $(\% \mathrm{BW})$ & -8 & 14 & -4 & 12 & -6 & 12 & -5 & 15 & -9 & 17 \\
\hline$F_{L G}$ & (\%BW) & -12 & 111 & -11 & 110 & -22 & 109 & -21 & 106 & -11 & 112 \\
\hline $\mathrm{M}_{\mathrm{AP}}$ & (\%BWm) & -1.91 & 0.80 & -1.51 & 0.78 & -2.20 & 0.45 & -0.84 & 1.39 & -1.53 & 0.68 \\
\hline $\mathrm{M}_{\mathrm{ML}}$ & $(\% \mathrm{BWm})$ & -3.01 & 9.78 & -0.73 & 13.17 & -4.25 & 5.23 & -0.70 & 10.46 & -2.36 & 8.03 \\
\hline$M_{L G}$ & $(\% \mathrm{BWm})$ & -0.80 & 0.82 & -0.63 & 0.87 & -0.66 & 0.52 & -1.01 & 0.89 & -0.76 & 1.18 \\
\hline $\mathrm{F}_{\mathrm{AP}}$ & (N) & -107.75 & 344.96 & -66.42 & 425.92 & -214.58 & 383.37 & -84.77 & 450.96 & -96.25 & 311.56 \\
\hline $\mathrm{F}_{\mathrm{ML}}$ & $(\mathrm{N})$ & -63.93 & 152.15 & -32.19 & 128.35 & -46.99 & 133.76 & -38.89 & 162.73 & -74.84 & 179.10 \\
\hline$F_{L G}$ & $(\mathrm{~N})$ & -96.08 & $1,129.25$ & -60.73 & $1,109.52$ & -175.22 & $1,170.03$ & -118.59 & $1,133.99$ & -60.35 & $1,070.45$ \\
\hline $\mathrm{M}_{\mathrm{AP}}$ & $(\mathrm{Nm})$ & -19.60 & 8.56 & -8.54 & 8.37 & -23.54 & 4.79 & -6.76 & 9.55 & -9.01 & 7.30 \\
\hline $\mathrm{M}_{\mathrm{ML}}$ & $(\mathrm{Nm})$ & -26.23 & 104.64 & -7.85 & 140.95 & -45.49 & 42.68 & -5.53 & 111.94 & -13.37 & 85.95 \\
\hline $\mathrm{M}_{\mathrm{LG}}$ & $(\mathrm{Nm})$ & -8.52 & 8.75 & -5.01 & 9.33 & -7.01 & 4.26 & -8.13 & 9.50 & -6.10 & 12.59 \\
\hline \multicolumn{12}{|l|}{ FFF } \\
\hline $\mathrm{F}_{\mathrm{AP}}$ & $(\% \mathrm{BW})$ & -13 & 41 & -10 & 48 & -15 & 48 & -14 & 39 & -11 & 39 \\
\hline $\mathrm{F}_{\mathrm{ML}}$ & $(\% \mathrm{BW})$ & -8 & 14 & -4 & 14 & -6 & 14 & -5 & 13 & -9 & 16 \\
\hline $\mathrm{F}_{\mathrm{LG}}$ & (\%BW) & -24 & 107 & -6 & 109 & -22 & 110 & -3 & 107 & -13 & 107 \\
\hline $\mathrm{M}_{\mathrm{AP}}$ & $(\% \mathrm{BWm})$ & -1.77 & 1.11 & -2.05 & 0.46 & -1.89 & 0.34 & -1.14 & 1.31 & -1.47 & 1.38 \\
\hline $\mathrm{M}_{\mathrm{ML}}$ & $(\% \mathrm{BWm})$ & -3.23 & 8.22 & -0.81 & 12.02 & -3.72 & 5.23 & -0.72 & 7.59 & -1.23 & 6.49 \\
\hline$M_{L G}$ & $(\% \mathrm{BWm})$ & -0.54 & 0.69 & -0.55 & 1.08 & -0.55 & 0.62 & -0.75 & 1.19 & -0.97 & 0.90 \\
\hline $\mathrm{F}_{\mathrm{AP}}$ & $(\mathrm{N})$ & -80.06 & 329.36 & -54.04 & 386.60 & -137.04 & 383.37 & -80.55 & 312.89 & -64.72 & 314.31 \\
\hline $\mathrm{F}_{\mathrm{ML}}$ & (N) & -66.25 & 152.52 & -34.75 & 148.01 & -46.99 & 150.37 & -36.75 & 143.76 & -71.68 & 169.28 \\
\hline $\mathrm{F}_{\mathrm{LG}}$ & $(\mathrm{N})$ & -251.75 & $1,091.39$ & -59.06 & $1,103.56$ & -175.22 & $1,178.84$ & -28.02 & $1,141.42$ & -107.35 & $1,074.47$ \\
\hline $\mathrm{M}_{\mathrm{AP}}$ & $(\mathrm{Nm})$ & -15.92 & 8.91 & -11.63 & 4.75 & -20.19 & 3.53 & -8.37 & 10.49 & -15.72 & 11.01 \\
\hline $\mathrm{M}_{\mathrm{ML}}$ & $(\mathrm{Nm})$ & -25.82 & 72.23 & -6.46 & 102.87 & -38.48 & 52.78 & -4.39 & 81.29 & -9.42 & 67.35 \\
\hline $\mathrm{M}_{\mathrm{LG}}$ & $(\mathrm{Nm})$ & -5.83 & 5.86 & -4.37 & 11.56 & -5.86 & 6.69 & -7.32 & 9.54 & -7.76 & 9.67 \\
\hline \multicolumn{12}{|c|}{ Difference } \\
\hline $\mathrm{F}_{\mathrm{AP}}$ & $(\% \mathrm{BW})$ & 3 & 2 & 2 & 9 & 5 & 0 & 1 & -3 & 6 & 6 \\
\hline $\mathrm{F}_{\mathrm{ML}}$ & $(\% \mathrm{BW})$ & 0 & 0 & 0 & 2 & 0 & 2 & 0 & -2 & 0 & -1 \\
\hline $\mathrm{F}_{\mathrm{LG}}$ & $(\% \mathrm{BW})$ & -12 & -4 & 4 & -1 & 0 & 1 & 17 & 1 & -3 & -5 \\
\hline $\mathrm{M}_{\mathrm{AP}}$ & $(\% \mathrm{BWm})$ & 0.15 & 0.31 & -0.54 & -0.32 & 0.31 & -0.11 & -0.29 & -0.08 & 0.06 & 0.70 \\
\hline $\mathrm{M}_{\mathrm{ML}}$ & $(\% \mathrm{BWm})$ & -0.22 & -1.55 & -0.07 & -1.15 & 0.53 & 0.00 & -0.03 & -2.86 & 1.13 & -1.53 \\
\hline$M_{L G}$ & $(\% \mathrm{BWm})$ & 0.25 & -0.13 & 0.08 & 0.21 & 0.11 & 0.10 & 0.26 & 0.30 & -0.21 & -0.27 \\
\hline $\mathrm{F}_{\mathrm{AP}}$ & $(\mathrm{N})$ & 27.69 & -15.60 & 12.39 & -39.32 & 77.55 & 0.00 & 4.22 & -138.07 & 31.53 & 2.75 \\
\hline $\mathrm{F}_{\mathrm{ML}}$ & $(\mathrm{N})$ & -2.32 & 0.37 & -2.56 & 19.66 & 0.00 & 16.61 & 2.14 & -18.97 & 3.15 & -9.82 \\
\hline $\mathrm{F}_{\mathrm{LG}}$ & $(\mathrm{N})$ & -155.67 & -37.86 & 1.67 & -5.95 & 0.00 & 8.81 & 90.57 & 7.43 & -46.99 & 4.02 \\
\hline $\mathrm{M}_{\mathrm{AP}}$ & $(\mathrm{Nm})$ & 3.68 & 0.34 & -3.09 & -3.62 & 3.35 & -1.26 & -1.62 & 0.94 & -6.71 & 3.71 \\
\hline $\mathrm{M}_{\mathrm{ML}}$ & $(\mathrm{Nm})$ & 0.41 & -32.41 & 1.39 & -38.08 & 7.00 & 10.09 & 1.15 & -30.65 & 3.95 & -18.60 \\
\hline$M_{L G}$ & $(\mathrm{Nm})$ & 2.69 & -2.89 & 0.65 & 2.23 & 1.15 & 2.43 & 0.82 & 0.04 & -1.66 & -2.92 \\
\hline
\end{tabular}


Table 4. Mean and standard deviation of onset expressed in percentage of the support phase of local extremum of forces and moments on the anteroposterior (AP), mediolateral (ML) and long (LG) axes of the implant fitted with usual (USU) and Free-Flow (FFF) feet during activities of daily living. H: High PV, L: Low PV, A: Above MCID, B: Below MCID.

\begin{tabular}{|c|c|c|c|c|c|c|c|c|c|c|}
\hline \multirow[b]{2}{*}{$\overline{\text { USU }}$} & \multicolumn{2}{|l|}{$\begin{array}{c}\text { Level } \\
\text { walking }\end{array}$} & \multicolumn{2}{|l|}{$\begin{array}{l}\text { Ascending } \\
\text { ramp }\end{array}$} & \multicolumn{2}{|l|}{$\begin{array}{l}\text { Descending } \\
\text { ramp }\end{array}$} & \multicolumn{2}{|l|}{$\begin{array}{l}\text { Ascending } \\
\text { stairs }\end{array}$} & \multicolumn{2}{|l|}{$\begin{array}{l}\text { Descending } \\
\text { stairs }\end{array}$} \\
\hline & & & & & & & & & & \\
\hline $\mathrm{F}_{\mathrm{AP} 1}$ & $12.99 \pm 6.97$ & $\mathrm{H}$ & - & - & - & - & - & - & - & - \\
\hline $\mathrm{F}_{\mathrm{AP} 2}$ & $83.23 \pm 7.42$ & $\mathrm{~L}$ & $75.12 \pm 18.13$ & $\mathrm{H}$ & $29.04 \pm 15.60$ & $\mathrm{H}$ & $40.92 \pm 30.22$ & $\mathrm{H}$ & $78.06 \pm 12.31$ & $\mathrm{~L}$ \\
\hline $\mathrm{F}_{\mathrm{ML1}}$ & $39.77 \pm 15.47$ & $\mathrm{H}$ & $35.82 \pm 15.94$ & $\mathrm{H}$ & $65.08 \pm 15.86$ & $\mathrm{H}$ & $37.85 \pm 19.26$ & $\mathrm{H}$ & $52.71 \pm 15.61$ & $\mathrm{H}$ \\
\hline $\mathrm{F}_{\mathrm{LG} 1}$ & $43.40 \pm 18.57$ & $\mathrm{H}$ & $59.65 \pm 20.91$ & $\mathrm{H}$ & $52.69 \pm 13.68$ & $\mathrm{H}$ & $75.62 \pm 14.16$ & $\mathrm{~L}$ & $40.76 \pm 17.05$ & $\mathrm{H}$ \\
\hline $\mathrm{M}_{\mathrm{AP} 1}$ & $93.94 \pm 12.79$ & $\mathrm{~L}$ & $73.82 \pm 20.38$ & $\mathrm{H}$ & $58.69 \pm 19.18$ & $\mathrm{H}$ & $80.46 \pm 22.53$ & $\mathrm{H}$ & $52.65 \pm 29.61$ & $\mathrm{H}$ \\
\hline $\mathrm{M}_{\mathrm{ML1}}$ & $13.06 \pm 4.43$ & $\mathrm{H}$ & $3.24 \pm 2.36$ & $\mathrm{H}$ & $47.58 \pm 20.87$ & $\mathrm{H}$ & $7.23 \pm 10.45$ & $\mathrm{H}$ & $73.47 \pm 13.20$ & $\mathrm{~L}$ \\
\hline $\mathrm{M}_{\mathrm{ML} 2}$ & $76.38 \pm 6.99$ & $\mathrm{~L}$ & $74.29 \pm 11.02$ & $\mathrm{~L}$ & $89.58 \pm 11.73$ & $\mathrm{~L}$ & $81.23 \pm 6.19$ & $\mathrm{~L}$ & - & - \\
\hline $\mathrm{M}_{\mathrm{LG} 1}$ & - & - & $68.82 \pm 13.65$ & $\mathrm{~L}$ & $87.54 \pm 15.17$ & $\mathrm{~L}$ & $15.15 \pm 11.34$ & $\mathrm{H}$ & - & - \\
\hline$M_{\mathrm{LG} 2}$ & - & - & - & - & - & - & $71.15 \pm 25.55$ & $\mathrm{H}$ & - & - \\
\hline \multicolumn{11}{|l|}{ FFF } \\
\hline $\mathrm{F}_{\mathrm{AP} 1}$ & $15.11 \pm 9.62$ & $\mathrm{H}$ & - & - & - & - & - & - & - & - \\
\hline $\mathrm{F}_{\mathrm{AP} 2}$ & $80.09 \pm 5.68$ & $\mathrm{~L}$ & $67.06 \pm 20.49$ & $\mathrm{H}$ & $20.09 \pm 13.20$ & $\mathrm{H}$ & $48.83 \pm 26.96$ & $\mathrm{H}$ & $71.00 \pm 15.40$ & $\mathrm{H}$ \\
\hline $\mathrm{F}_{\mathrm{ML1}}$ & $43.41 \pm 20.85$ & $\mathrm{H}$ & $40.39 \pm 17.14$ & $\mathrm{H}$ & $61.77 \pm 23.19$ & $\mathrm{H}$ & $41.39 \pm 17.40$ & $\mathrm{H}$ & $51.16 \pm 20.75$ & $\mathrm{H}$ \\
\hline $\mathrm{F}_{\mathrm{LG} 1}$ & $45.68 \pm 19.78$ & $\mathrm{H}$ & $63.11 \pm 18.32$ & $\mathrm{H}$ & $46.43 \pm 19.88$ & $\mathrm{H}$ & $71.44 \pm 15.25$ & $\mathrm{H}$ & $42.21 \pm 21.27$ & $\mathrm{H}$ \\
\hline $\mathrm{M}_{\mathrm{AP} 1}$ & $72.30 \pm 20.02$ & $\mathrm{H}$ & $64.06 \pm 15.86$ & $\mathrm{H}$ & $63.89 \pm 25.10$ & $\mathrm{H}$ & $60.11 \pm 28.41$ & $\mathrm{H}$ & $34.21 \pm 35.11$ & $\mathrm{H}$ \\
\hline $\mathrm{M}_{\mathrm{ML1}}$ & $11.50 \pm 3.68$ & $\mathrm{H}$ & $2.83 \pm 1.50$ & $\mathrm{H}$ & $26.51 \pm 10.93$ & $\mathrm{H}$ & $5.83 \pm 11.56$ & $\mathrm{H}$ & $70.74 \pm 13.73$ & $\mathrm{~L}$ \\
\hline $\mathrm{M}_{\mathrm{ML2}}$ & $76.95 \pm 7.00$ & $\mathrm{~L}$ & $76.33 \pm 5.82$ & $\mathrm{~L}$ & $88.17 \pm 11.81$ & $\mathrm{~L}$ & $80.39 \pm 4.03$ & $\mathrm{~L}$ & - & - \\
\hline$M_{L G 1}$ & - & - & $68.44 \pm 12.28$ & $\mathrm{~L}$ & $87.43 \pm 11.84$ & $\mathrm{~L}$ & $27.67 \pm 15.77$ & $\mathrm{H}$ & - & - \\
\hline $\mathrm{M}_{\mathrm{LG} 2}$ & - & - & - & - & - & - & $77.22 \pm 17.72$ & $\mathrm{H}$ & - & - \\
\hline \multicolumn{11}{|c|}{ Difference } \\
\hline $\mathrm{F}_{\mathrm{AP1}}$ & 2.12 & A & - & - & - & - & - & - & - & - \\
\hline $\mathrm{F}_{\mathrm{AP} 2}$ & -3.14 & B & -8.06 & A & -8.95 & A & 7.91 & A & -7.06 & B \\
\hline $\mathrm{F}_{\mathrm{ML1}}$ & 3.64 & B & 4.57 & A & -3.31 & B & 3.54 & B & -1.55 & B \\
\hline $\mathrm{F}_{\text {LG1 }}$ & 2.27 & B & 3.46 & B & -6.26 & A & -4.17 & B & 1.45 & B \\
\hline $\mathrm{M}_{\mathrm{AP} 1}$ & -21.64 & A & -9.77 & A & 5.19 & B & -20.35 & A & -18.44 & A \\
\hline $\mathrm{M}_{\mathrm{ML1}}$ & -1.56 & A & -0.40 & A & -21.06 & A & -1.40 & A & -2.73 & B \\
\hline $\mathrm{M}_{\mathrm{ML2}}$ & 0.57 & B & 2.04 & B & -1.41 & B & -0.84 & B & - & - \\
\hline$M_{L G 1}$ & - & - & -0.38 & B & -0.11 & B & 12.51 & A & - & - \\
\hline $\mathrm{M}_{\mathrm{LG} 2}$ & - & - & - & - & - & - & 6.07 & $\mathrm{~B}$ & - & - \\
\hline
\end{tabular}


Table 5. Mean and standard deviation of magnitude of local extremum of forces in \% BW and moments in \% BWm on the anteroposterior (AP), mediolateral (ML) and long (LG) axes of the implant fitted with usual (USU) and Free-Flow (FFF) feet during activities of daily living. H: High PV, L: Low PV, A: Above MCID, B: Below MCID.

\begin{tabular}{|c|c|c|c|c|c|c|c|c|c|c|}
\hline \multirow[b]{2}{*}{ USU } & \multicolumn{2}{|l|}{$\begin{array}{c}\text { Level } \\
\text { walking }\end{array}$} & \multicolumn{2}{|l|}{$\begin{array}{c}\text { Ascending } \\
\text { ramp }\end{array}$} & \multicolumn{2}{|l|}{$\begin{array}{l}\text { Descending } \\
\text { ramp }\end{array}$} & \multicolumn{2}{|l|}{$\begin{array}{c}\text { Ascending } \\
\text { stairs }\end{array}$} & \multicolumn{2}{|c|}{$\begin{array}{c}\text { Descending } \\
\text { stairs }\end{array}$} \\
\hline & & & & & & & & & & \\
\hline $\mathrm{F}_{\mathrm{AP} 1}$ & $-9.65 \pm 4.85$ & $\mathrm{H}$ & - & - & - & - & - & - & - & - \\
\hline $\mathrm{F}_{\mathrm{AP} 2}$ & $22.07 \pm 10.15$ & $\mathrm{H}$ & $21.83 \pm 13.87$ & $\mathrm{H}$ & $-13.56 \pm 5.40$ & $\mathrm{H}$ & $27.23 \pm 11.86$ & $\mathrm{H}$ & $13.78 \pm 11.24$ & $\mathrm{H}$ \\
\hline $\mathrm{F}_{\mathrm{ML1}}$ & $8.22 \pm 2.53$ & $\mathrm{H}$ & $7.06 \pm 3.27$ & $\mathrm{H}$ & $7.87 \pm 2.54$ & $\mathrm{H}$ & $9.18 \pm 4.09$ & $\mathrm{H}$ & $7.89 \pm 3.96$ & $\mathrm{H}$ \\
\hline $\mathrm{F}_{\text {LG1 }}$ & $102.05 \pm 4.36$ & $\mathrm{~L}$ & $100.10 \pm 5.92$ & $\mathrm{~L}$ & $98.28 \pm 13.22$ & $\mathrm{~L}$ & $97.53 \pm 4.90$ & $\mathrm{~L}$ & $100.25 \pm 8.78$ & $\mathrm{~L}$ \\
\hline $\mathrm{M}_{\mathrm{AP} 1}$ & $0.11 \pm 0.27$ & $\mathrm{H}$ & $-0.90 \pm 0.65$ & $\mathrm{H}$ & $-1.33 \pm 0.57$ & $\mathrm{H}$ & $0.68 \pm 0.57$ & $\mathrm{H}$ & $0.99 \pm 0.52$ & $\mathrm{H}$ \\
\hline $\mathbf{M}_{\mathrm{ML1}}$ & $-2.00 \pm 0.49$ & $\mathrm{H}$ & $-0.10 \pm 0.35$ & $\mathrm{H}$ & $-3.53 \pm 0.63$ & $\mathrm{~L}$ & $0.03 \pm 0.44$ & $\mathrm{H}$ & $3.65 \pm 2.73$ & $\mathrm{H}$ \\
\hline $\mathbf{M}_{\mathrm{ML} 2}$ & $7.94 \pm 0.78$ & $\mathrm{~L}$ & $10.99 \pm 0.91$ & $\mathrm{~L}$ & $1.91 \pm 1.99$ & $\mathrm{H}$ & $7.89 \pm 1.85$ & $\mathrm{H}$ & - & - \\
\hline$M_{L G 1}$ & - & - & $0.55 \pm 0.22$ & $\mathrm{H}$ & $0.22 \pm 0.10$ & $\mathrm{H}$ & $-0.34 \pm 0.29$ & $\mathrm{H}$ & - & - \\
\hline$M_{\text {LG2 }}$ & - & - & - & - & - & - & $0.41 \pm 0.34$ & $\mathrm{H}$ & - & - \\
\hline \multicolumn{11}{|l|}{ FFF } \\
\hline $\mathrm{F}_{\mathrm{AP} 1}$ & $-7.49 \pm 3.92$ & $\mathrm{H}$ & - & - & - & - & - & - & - & - \\
\hline $\mathrm{F}_{\mathrm{AP} 2}$ & $22.87 \pm 8.69$ & $\mathrm{H}$ & $28.26 \pm 11.33$ & $\mathrm{H}$ & $-9.03 \pm 5.34$ & $\mathrm{H}$ & $26.58 \pm 11.95$ & $\mathrm{H}$ & $19.31 \pm 12.45$ & $\mathrm{H}$ \\
\hline $\mathrm{F}_{\mathrm{ML} 1}$ & $8.23 \pm 3.20$ & $\mathrm{H}$ & $7.19 \pm 4.02$ & $\mathrm{H}$ & $7.09 \pm 3.25$ & $\mathrm{H}$ & $7.15 \pm 3.40$ & $\mathrm{H}$ & $7.76 \pm 4.38$ & $\mathrm{H}$ \\
\hline $\mathrm{F}_{\text {LG1 }}$ & $99.69 \pm 4.60$ & $\mathrm{~L}$ & $100.20 \pm 5.15$ & $\mathrm{~L}$ & $98.26 \pm 9.74$ & $\mathrm{~L}$ & $98.50 \pm 4.77$ & $\mathrm{~L}$ & $97.92 \pm 9.24$ & $\mathrm{~L}$ \\
\hline $\mathrm{M}_{\mathrm{AP} 1}$ & $0.90 \pm 0.56$ & $\mathrm{H}$ & $-1.01 \pm 0.73$ & $\mathrm{H}$ & $-0.81 \pm 0.65$ & $\mathrm{H}$ & $0.66 \pm 0.45$ & $\mathrm{H}$ & $0.68 \pm 0.55$ & $\mathrm{H}$ \\
\hline $\mathbf{M}_{\mathrm{ML1}}$ & $-1.63 \pm 0.37$ & $\mathrm{H}$ & $-0.01 \pm 0.18$ & $\mathrm{H}$ & $-2.61 \pm 0.88$ & $\mathrm{H}$ & $-0.10 \pm 0.25$ & $\mathrm{H}$ & $3.98 \pm 1.98$ & $\mathrm{H}$ \\
\hline $\mathrm{M}_{\mathrm{ML} 2}$ & $7.19 \pm 0.70$ & $\mathrm{~L}$ & $9.86 \pm 1.44$ & $\mathrm{~L}$ & $1.46 \pm 1.82$ & $\mathrm{H}$ & $5.72 \pm 1.76$ & $\mathrm{H}$ & - & - \\
\hline$M_{\text {LG1 }}$ & - & - & $0.51 \pm 0.31$ & $\mathrm{H}$ & $0.26 \pm 0.14$ & $\mathrm{H}$ & $-0.44 \pm 0.18$ & $\mathrm{H}$ & - & - \\
\hline$M_{\text {LG2 }}$ & - & - & - & - & - & - & $0.44 \pm 0.35$ & $\mathrm{H}$ & - & - \\
\hline \multicolumn{11}{|c|}{ Difference } \\
\hline $\mathrm{F}_{\mathrm{AP} 1}$ & 2.16 & A & - & - & - & - & - & - & - & - \\
\hline $\mathrm{F}_{\mathrm{AP} 2}$ & 0.80 & B & 6.43 & A & 4.53 & A & -0.65 & B & 5.53 & A \\
\hline $\mathrm{F}_{\mathrm{ML} 1}$ & 0.01 & B & 0.14 & B & -0.78 & B & -2.04 & A & -0.14 & B \\
\hline $\mathrm{F}_{\text {LG1 }}$ & -2.35 & B & 0.10 & B & -0.03 & B & 0.97 & B & -2.33 & B \\
\hline $\mathrm{M}_{\mathrm{AP} 1}$ & 0.79 & A & -0.12 & A & 0.52 & A & -0.01 & B & -0.32 & A \\
\hline $\mathbf{M}_{\mathrm{ML1}}$ & 0.36 & A & 0.09 & A & 0.92 & A & -0.13 & A & 0.33 & B \\
\hline $\mathrm{M}_{\mathrm{ML} 2}$ & -0.75 & B & -1.13 & A & -0.45 & A & -2.17 & A & - & - \\
\hline$M_{L G 1}$ & - & - & -0.04 & B & 0.04 & A & -0.11 & A & - & - \\
\hline$M_{\mathrm{LG} 2}$ & - & - & - & - & - & - & 0.04 & B & - & - \\
\hline
\end{tabular}


Table 6. Mean and standard deviation of impulse on the anteroposterior (IAP), mediolateral (IML) and long (ILG) axes expressed in \%BWs during support phase while using usual (USU) and Free-Flow (FFF) feet during activities of daily living. H: High PV, L: Low PV, A: Above MCID, B: Below MCID.

\begin{tabular}{ccccccccccc}
\hline & $\begin{array}{c}\text { Level } \\
\text { walking }\end{array}$ & $\begin{array}{c}\text { Ascending } \\
\text { ramp }\end{array}$ & $\begin{array}{c}\text { Descending } \\
\text { ramp }\end{array}$ & $\begin{array}{c}\text { Ascending } \\
\text { stairs }\end{array}$ & \multicolumn{2}{c}{$\begin{array}{c}\text { Descending } \\
\text { stairs }\end{array}$} \\
\hline USU & & & & & & & & & & \\
I $_{\mathrm{AP}}$ & $9.91 \pm 3.83$ & $\mathrm{H}$ & $13.45 \pm 7.59$ & $\mathrm{H}$ & $9.48 \pm 3.25$ & $\mathrm{H}$ & $16.87 \pm 7.09$ & $\mathrm{H}$ & $8.77 \pm 3.39$ & $\mathrm{H}$ \\
$\mathrm{I}_{\mathrm{ML}}$ & $3.79 \pm 1.69$ & $\mathrm{H}$ & $4.67 \pm 1.81$ & $\mathrm{H}$ & $3.92 \pm 1.63$ & $\mathrm{H}$ & $5.90 \pm 3.01$ & $\mathrm{H}$ & $4.17 \pm 2.77$ & $\mathrm{H}$ \\
$\mathrm{I}_{\mathrm{LG}}$ & $57.12 \pm 5.91$ & $\mathrm{~L}$ & $76.63 \pm 19.27$ & $\mathrm{H}$ & $56.76 \pm 12.65$ & $\mathrm{H}$ & $78.22 \pm 23.45$ & $\mathrm{H}$ & $54.48 \pm 10.15$ & $\mathrm{~L}$ \\
\hline FFF & & & & & & & & & & \\
I $_{\mathrm{AP}}$ & $8.98 \pm 3.59$ & $\mathrm{H}$ & $16.86 \pm 4.97$ & $\mathrm{H}$ & $7.79 \pm 3.77$ & $\mathrm{H}$ & $15.66 \pm 6.28$ & $\mathrm{H}$ & $9.33 \pm 5.76$ & $\mathrm{H}$ \\
$\mathrm{I}_{\mathrm{ML}}$ & $3.84 \pm 1.46$ & $\mathrm{H}$ & $4.03 \pm 3.01$ & $\mathrm{H}$ & $3.26 \pm 2.11$ & $\mathrm{H}$ & $3.80 \pm 2.73$ & $\mathrm{H}$ & $3.64 \pm 2.32$ & $\mathrm{H}$ \\
$\mathrm{I}_{\mathrm{LG}}$ & $58.25 \pm 6.32$ & $\mathrm{~L}$ & $69.77 \pm 16.79$ & $\mathrm{H}$ & $52.20 \pm 10.60$ & $\mathrm{H}$ & $64.19 \pm 11.81$ & $\mathrm{~L}$ & $51.57 \pm 9.12$ & $\mathrm{~L}$ \\
\hline Difference & & & & & & & & & \\
$\mathrm{I}_{\mathrm{AP}}$ & -0.931 & $\mathrm{~B}$ & 3.416 & $\mathrm{~A}$ & -1.687 & $\mathrm{~A}$ & -1.213 & $\mathrm{~B}$ & 0.562 & $\mathrm{~B}$ \\
$\mathrm{I}_{\mathrm{ML}}$ & 0.056 & $\mathrm{~B}$ & -0.641 & $\mathrm{~A}$ & -0.663 & $\mathrm{~A}$ & -2.097 & $\mathrm{~A}$ & -0.523 & $\mathrm{~A}$ \\
$\mathrm{I}_{\mathrm{LG}}$ & 1.130 & $\mathrm{~B}$ & -6.859 & $\mathrm{~B}$ & -4.567 & $\mathrm{~B}$ & -14.030 & $\mathrm{~A}$ & -2.918 & $\mathrm{~B}$ \\
\hline
\end{tabular}

